\title{
Article
}

\section{Intracellular Galectin-9 Controls Dendritic Cell Function by Maintaining Plasma Membrane Rigidity}

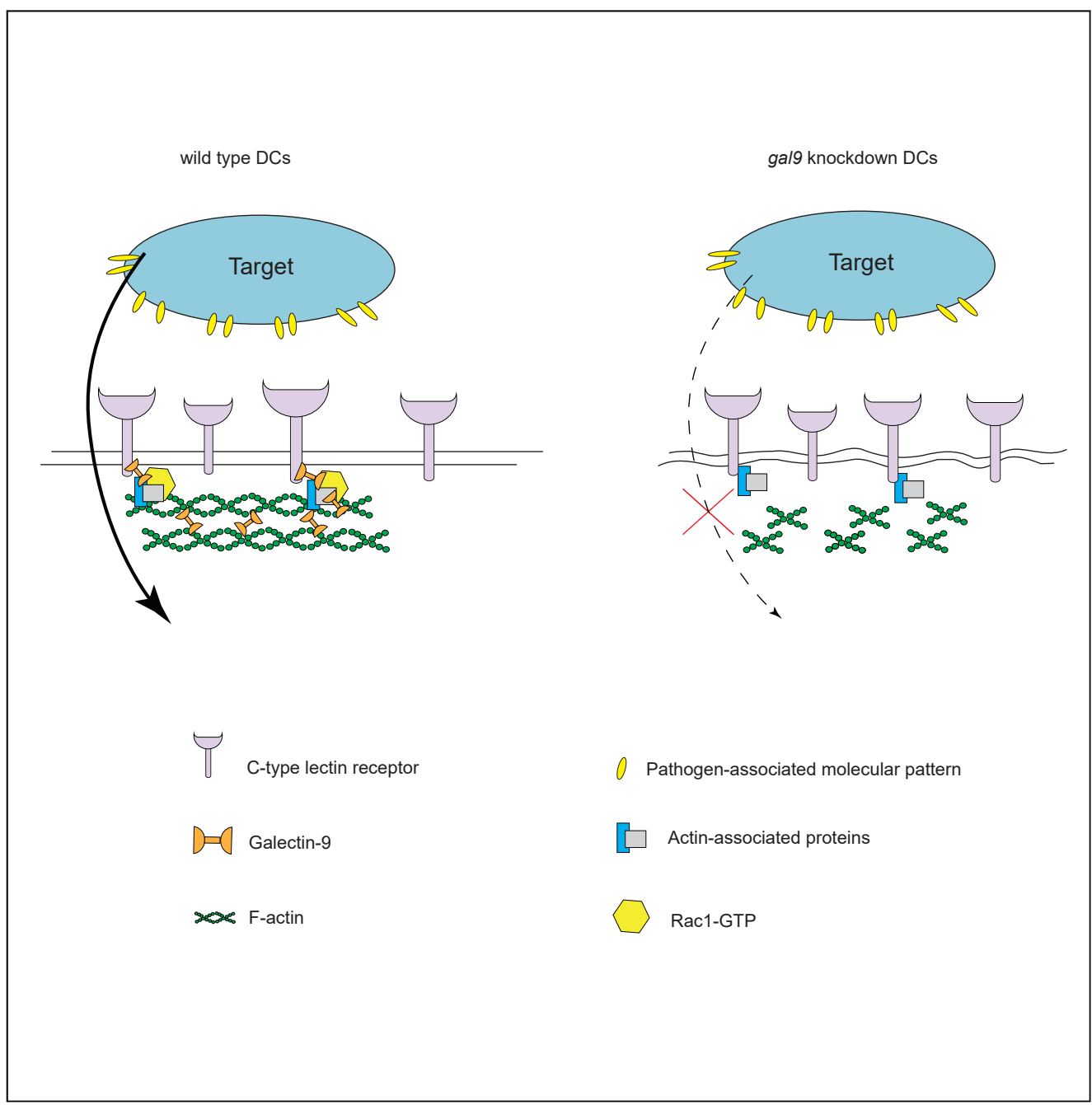

Laia Querol Cano, Oya Tagit, Yusuf Dolen, ..., Alessandra Cambi, Carl G. Figdor, Annemiek B. van Spriel

annemiek.vanspriel@ radboudumc.nl

HIGHLIGHTS Galectin-9 is required for particle uptake by both human and murine dendritic cells

Galectin-9 is associated with the cortical actin cytoskeleton

Galectin-9 controls plasma membrane integrity and rigidity

Galectin-9 regulates Rac1 activity and recruitment to nascent phagosomes 


\title{
Article
}

\section{Intracellular Galectin-9 Controls Dendritic Cell Function by Maintaining Plasma Membrane Rigidity}

\author{
Laia Querol Cano, ${ }^{1}$ Oya Tagit, 1,6 Yusuf Dolen, ${ }^{1,6}$ Anne van Duffelen, ${ }^{1}$ Shannon Dieltjes, ${ }^{1}$ Sonja I. Buschow, ${ }^{2}$ \\ Toshiro Niki, ${ }^{3,4}$ Mitsuomi Hirashima, ${ }^{3,4}$ Ben Joosten, ${ }^{5}$ Koen van den Dries, ${ }^{5}$ Alessandra Cambi, ${ }^{5}$ Carl G. Figdor, 1,7 \\ and Annemiek B. van Spriel $1,7,8, *$
}

\begin{abstract}
SUMMARY
Endogenous extracellular Galectins constitute a novel mechanism of membrane protein organization at the cell surface. Although Galectins are also highly expressed intracellularly, their cytosolic functions are poorly understood. Here, we investigated the role of Galectin-9 in dendritic cell (DC) surface organization and function. By combining functional, super-resolution and atomic force microscopy experiments to analyze membrane stiffness, we identified intracellular Galectin- 9 to be indispensable for plasma membrane integrity and structure in DCs. Galectin-9 knockdown studies revealed intracellular Galectin-9 to directly control cortical membrane structure by modulating Rac1 activity, providing the underlying mechanism of Galectin-9-dependent actin cytoskeleton organization. Consequent to its role in maintaining plasma membrane structure, phagocytosis studies revealed that Galectin-9 was essential for C-type-lectin receptor-mediated pathogen uptake by DCs. This was confirmed by the impaired phagocytic capacity of Galectin-9-null murine DCs. Together, this study demonstrates a novel role for intracellular Galectin-9 in modulating DC function, which may be evolutionarily conserved.
\end{abstract}

\section{INTRODUCTION}

Dendritic cells (DCs) constitute the major group of antigen-presenting cells that constantly patrol the body for microbes and are essential for linking innate and adaptive immune responses (Banchereau and Steinman, 1998). DCs are equipped with a diverse membrane receptor repertoire to take up pathogens including Toll-like receptors, scavenger receptors, and C-type lectins, such as the mannose receptor and the dendritic cell-specific intercellular adhesion molecule grabbing non-integrin receptor (DCSIGN) (Banchereau et al., 2000; Savina and Amigorena, 2007; Buschow et al., 2012; Heinsbroek et al., 2008; Geijtenbeek et al., 2000). Engagement of these receptors with their ligand is accompanied by cytoskeletal changes, which allow for the capture and engulfment of phagocytic targets (Sano et al., 2003; Baranov et al., 2016). Actin polymerization is instrumental in forming a nascent phagosome for pathogen engulfment, and actin-driven mechanical forces enable pathogen internalization (May et al., 2000). In addition, phagocytosis is dependent on plasma membrane organization and loss of membrane structure results in impaired pathogen recognition, defective migration, and compromised immunological synapse formation (Alvarez et al., 2008; Heuze et al., 2013; Buschow et al., 2012). Galectins, a family of B-galactoside-binding proteins, have been recently identified as a novel mechanism of membrane organization (Lajoie et al., 2009; Elola et al., 2015; Nabi et al., 2015) due to their ability to interact with and cross-link specific carbohydrate structures. As such, Galectins can simultaneously interact with multiple glycoconjugates, thereby regulating the dynamics of glycosylated-binding partners, limiting receptor internalization, and establishing membrane microdomains (Elola et al., 2015). Notably, Galectins are also abundantly expressed intracellularly, although their cytosolic functions are not well characterized (Hsu et al., 2015a; Johannes et al., 2018; Liu et al., 2002; Liu and Rabinovich, 2005). Recently, Galectins have been discovered as novel regulators of several immune processes, such as T cell homeostasis, inflammation, and immune disorders (Sundblad et al., 2017; Thiemann and Baum, 2016; de Oliveira et al., 2015; Rabinovich and Toscano, 2009).

Galectin-9 was first discovered as an eosinophil chemoattractant, and to date, most studies have focused on studying Galectin-9 in inflammation or infection processes (Jost et al., 2013; Curciarello et al., 2014; Hsu et al., 2015b). Extracellular Galectin-9 has been implicated in inhibiting T cell immunity by promoting T cell
1Department of Tumour Immunology, Radboud Institute for Molecular Life Sciences, Radboud University Medical Center, Geert Grooteplein 26-28, Nijmegen 6525 GA, The Netherlands

2Department of Gastroenterology and Hepatology, Erasmus MC-University Medical Center, Wytemaweg 80, Rotterdam 3015 CN, The Netherlands

${ }^{3}$ GalPharma Co., Ltd. Takamatsu, Kagawa 761-0301, Japan

${ }^{4}$ Department of Immunology and Immunopathology, Faculty of Medicine, Kagawa University, Takamatsu, Kagawa, 761-0793, Japan

${ }^{5}$ Department of Cell Biology, Radboud Institute for Molecular Life Sciences, Radboud University Medical Center, Geert Grooteplein 26-28, 6525 GA Nijmegen, The Netherlands

${ }^{6}$ These authors contributed equally

${ }^{7}$ These authors contributed equally

\&Lead Contact

*Correspondence: annemiek.vanspriel@ radboudumc.nl

https://doi.org/10.1016/j.isci. 2019.11.019 


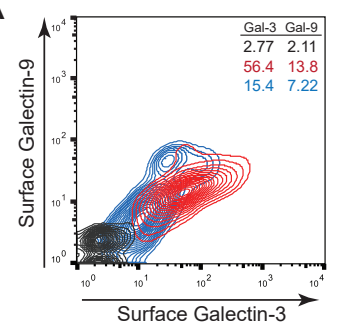

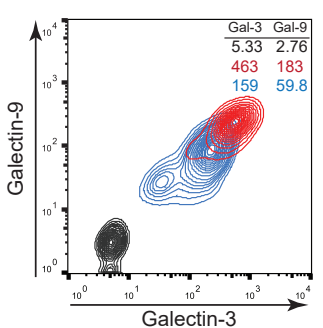

C
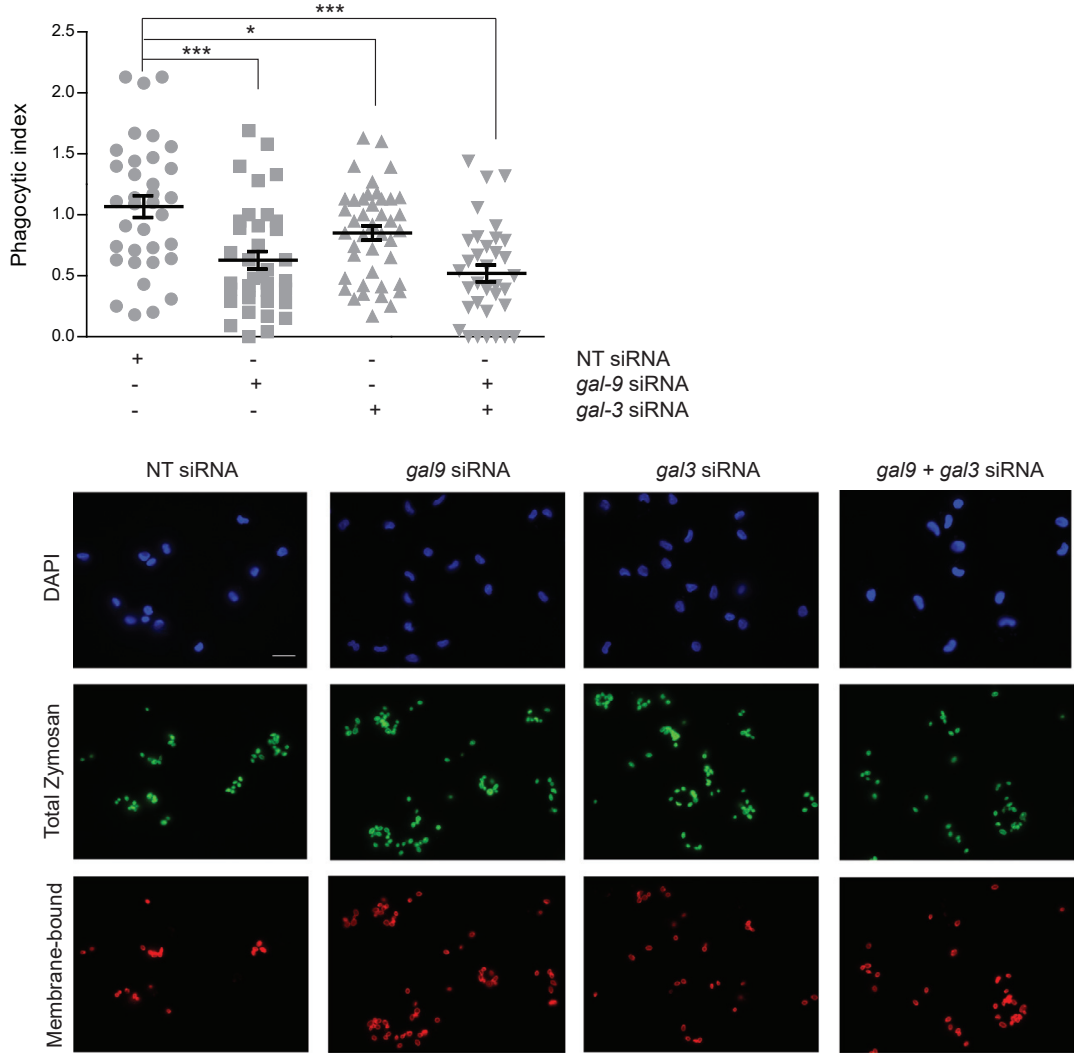

E

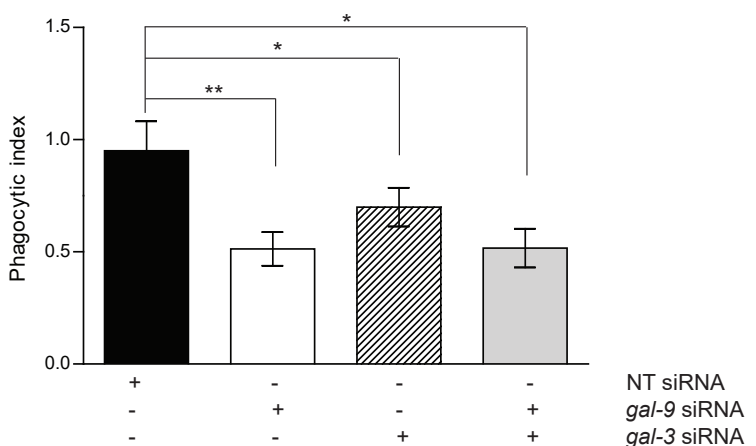

Figure 1. Galectin-9 Is Required for Dendritic Cell Function

( $A$ and $B$ ) moDCs were transfected with gal9 siRNA and/or gal3 siRNA or a non-targeting siRNA (NT). Surface only (A) and total (B) Galectin-9 and Galectin-3 knockdown were confirmed by flow cytometry $48 \mathrm{~h}$ after transfection. Red population, NT siRNA; blue population, gal9 and gal3 siRNAs transfected moDCs; black population, isotype control. Numbers in inset indicate geometrical mean fluorescence intensity.

(C) NT, gal9, and/or gal3 siRNA-transfected cells were challenged with zymosan for 60 min, after which cells were fixed, stained, and the phagocytic index calculated. Graphs show representative results for one donor. Each dot represents 


\section{iScience}

Figure 1. Continued

phagocytic index obtained for one image field; 20-30 image fields were analyzed per condition, and each image field contained 10-20 cells.

(D) Representative images from results shown in (C)

(E) Quantification and statistical analysis of experiments depicted in (D). Results show the mean \pm SEM for four

independent donors. Unpaired Student's t test was conducted between NT and gal9 siRNA- and between NT and gal3 siRNA-transfected cells.

${ }^{*} p<0.05,{ }^{* *} p<0.005,{ }^{* *} p<0.0001$. See also Figure S1.

apoptosis and differentiation into regulatory T cells (Anderson et al., 2007; Bi et al., 2008; Zhu et al., 2005). Furthermore, extracellular Galectin-9 acts as a suppressor of B cell signaling by binding to the B cell receptor (Cao et al., 2018; Giovannone et al., 2018). Although these studies indicate that Galectin-9 plays an inhibitory role on lymphocytes, its function in myeloid cells remains poorly understood. Moreover, Galectin-9 is also highly expressed intracellularly, and although implicated in protein-protein interactions and mRNA splicing (Liu et al., 2002; Sundblad et al., 2017; Heusschen et al., 2013), the function of cytosolic Galectin-9 in the immune system continues to be ill defined.

Here, we demonstrate that intracellular Galectin-9 is essential for sustaining cortical actin cytoskeleton rigidity and phagocytosis in DCs. Our work indicates a novel evolutionary conserved mechanism by which intracellular Galectins stabilize plasma membrane structure by actin cytoskeleton reorganization.

\section{RESULTS}

\section{Galectins Are Essential in Governing Human Dendritic Cell Function}

The role of Galectins in the initiation of the immune response is poorly understood, and although Galectin3 has been implicated in macrophage-mediated uptake in mice (Sano et al., 2003), few studies have been performed to elucidate Galectin function in DCs (de Kivit et al., 2017; Leskela et al., 2015; Hsu et al., 2015b; Dai et al., 2005). To address this question, we generated DCs lacking Galectin-3 and/or Galectin-9 by electroporating human monocyte-derived dendritic cells (moDCs) with either a specific galectin small interfering RNA (siRNA) (gal3 and/or gal9) or a non-targeting (NT) siRNA control before challenge them with fluorescein isothiocyanate (FITC)-labeled zymosan particles, a fungal cell wall extract (de la Rosa et al., 2005). Subsequent immunolabeling without permeabilization using an antibody directed against FITC allowed for selective labeling of membrane-bound particles. Galectin-9 and Galectin-3 protein knockdowns were confirmed by flow cytometry showing that both proteins were depleted to a similar extent (70\%, Figures $1 \mathrm{~A}$ and $1 \mathrm{~B})$. The efficiency of Galectin knockdown was comparable between cells transfected with a single siRNA or with dual siRNA, and Galectin-9 knockdown (Gal-9 KD) did not affect Galectin-3 expression, or vice versa (Figure S1). Depletion of Galectin-9 impaired particle uptake to a greater extent when compared with that observed upon Galectin-3 knockdown (Figures 1C, 1D, and 1E). Moreover, there was no additive effect of knocking down both Galectin-9 and Galectin-3 (Figure 1E). Taken together, these data demonstrate that Galectins are required for phagocytosis by DCs, and indicates that Galectin-9 is a major player in this process.

\section{Galectin-9 Is Essential for Phagocytosis by Dendritic Cells}

We previously identified Galectin-9 as part of the DC-SIGN-mediated, a phagocytic receptor present in immature DCs, phagosomes, although no functional studies were performed to assess the role of Galectin-9 in DC function (Buschow et al., 2012; Manzo et al., 2012; Liu et al., 2017; Cambi et al., 2003; Geijtenbeek et al., 2000). Co-immunoprecipitation experiments revealed DC-SIGN association with Galectin-9 in DCs, demonstrating their molecular interaction (Figure 2A). To examine whether this interaction occurs in the cytosolic compartment and/or at the extracellular matrix, co-immunoprecipitations were performed on lactose-treated moDCs and in the presence of lactose to prevent unspecific binding of Galectin-9 to DC-SIGN during cell lysis. Lactose impairs cell surface glycan-based interactions mediated by Galectins by competing for their major ligands, which dissociates Galectins from the cell surface (Lajoie et al., 2007; Cambi et al., 2009). As shown, addition of lactose successfully removed Galectin-9 from the surface of moDCs (Figure S2A). Nonetheless, Galectin-9 was found to still bind DC-SIGN, albeit to a lesser extent than in the untreated control (Figure 2B). These data indicate that Galectin-9 binds to DC-SIGN both extraand intracellularly. To investigate the role of Galectin-9 in DC-SIGN-mediated phagocytosis, Gal-9 KD and NT control (referred to as wild-type [WT]) DCs were challenged with zymosan particles. Galectin-9 protein knockdown (90\%) was confirmed by flow cytometry (Figure S2B) and western blotting (Figure S2C). No 
A

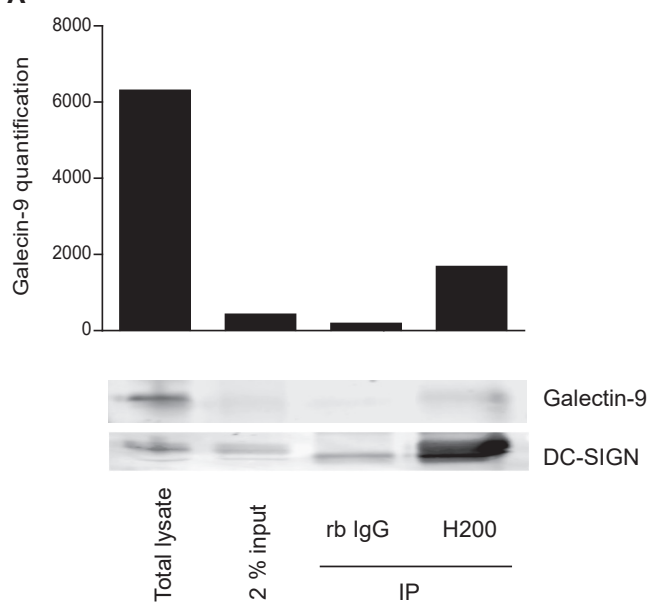

B
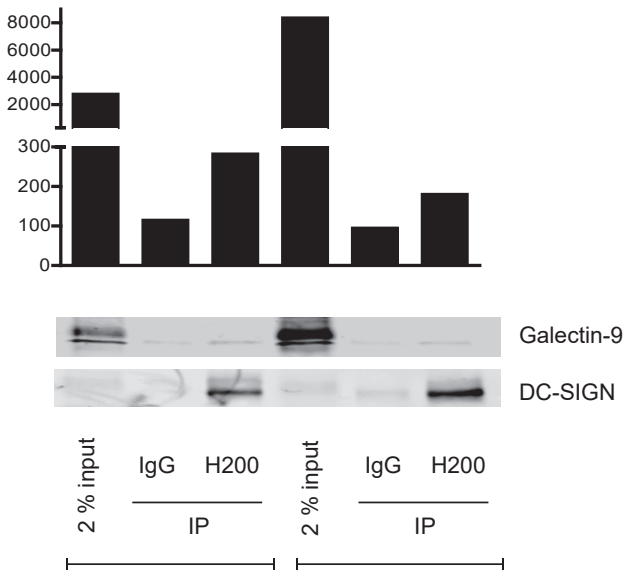

C
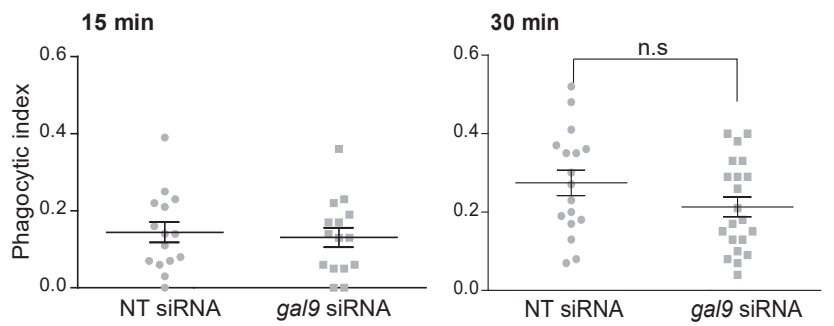

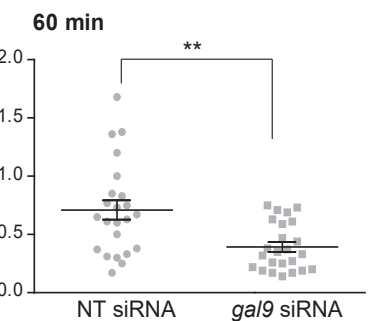

D

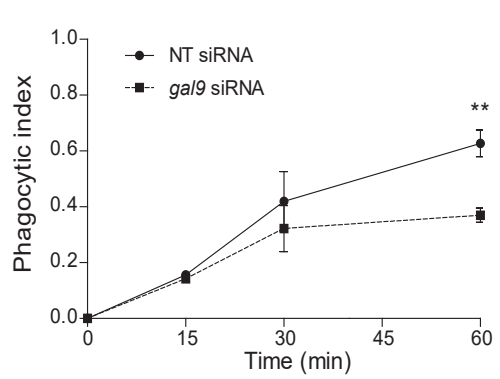

E

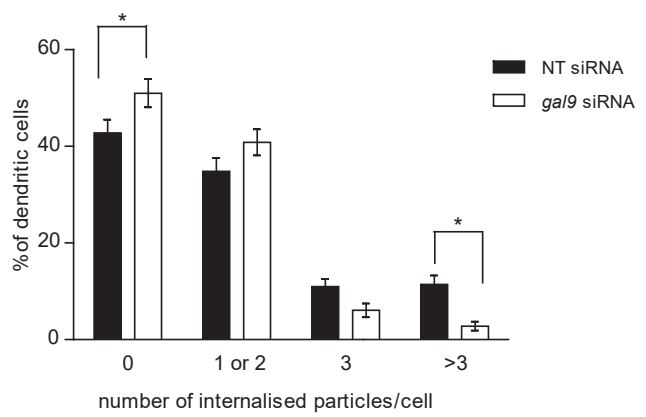

Figure 2. Galectin-9 Is Required for Optimal Phagocytic Capacity in DCs

(A) moDCs were lysed and whole-cell extract prepared for incubation with anti-DC-SIGN antibody (H200) or isotype control (total rabbit IgG). Immunoprecipitated (IP) complexes were resolved and probed with DC-SIGN- and Galectin-9specific antibodies. Graph shows quantification of Galectin-9 content of each sample using ImageJ.

(B) moDCs were treated with $35 \mathrm{mM}$ lactose for $48 \mathrm{~h}$ before being lysed as per (A). IP complexes were resolved and probed with DC-SIGN- and Galectin-9 specific antibodies. Graph shows quantification of Galectin-9 content of each sample using ImageJ.

(C) NT or gal9 siRNA-transfected cells were challenged with zymosan for the indicated time points. After this time, cells were fixed, stained, and phagocytic indexes calculated for each time point. Graphs show representative results for one donor. Each dot represents phagocytic index obtained for each microscopic field, each of which contained 10-20 cells. (D) Quantification and statistical analysis of experiments shown in (C). Twenty frames were analyzed for each donor and transfection. Results show the mean value \pm SEM for four independent donors. Unpaired Student's $t$ test was conducted between NT and gal9 siRNA-transfected cells for all time points. 
Figure 2. Continued

(E) NT or gal9 siRNA-transfected cells were challenged as per (C) and the number of internalized zymosan particles quantified for each frame. Ten to twenty frames were analyzed for each condition. Data represent mean percentage of DCs that had internalized the specified number of particles of one representative donor out of three independent experiments. For statistical analysis two-way ANOVA followed by a Bonferroni post hoc test was applied. n.s.: $p>0.05 ;{ }^{*} p<0.05,{ }^{* *} p<0.005$. See also Figures $S 2-S 4$.

significant differences in zymosan binding were observed between NT and gal9 siRNA-transfected DCs (Figure S2D), implying that Galectin-9 is not required for particle binding. To study the involvement of Galectin-9 in particle uptake, the phagocytic index was calculated for each of the conditions and specified time points (Figures 2C, 2D, and S2E). Gal-9 KD resulted in impaired zymosan internalization 60 min after challenging moDCs (Figure 2D). Quantification of the number of particles internalized per cell revealed that the impaired uptake upon Gal-9 KD is likely due to a decrease in the number of zymosan particles internalized per cell rather than a decrease in the total amount of cells able to uptake particles (Figure 2E). Gal-9 KD did not alter DC-SIGN membrane expression or receptor internalization excluding that the uptake defect was due to deficient receptor surface levels (Figure S3). Next, WT and Gal-9 KD moDCs were incubated with a DC-SIGN-blocking antibody (clone AZN-D1) or isotype control before challenging them with zymosan particles. AZN-D1 does not induce DC-SIGN signaling and has a modified Fc region that cannot be recognized by the Fc receptors expressed on DCs (Geijtenbeek et al., 2000; Tacken et al., 2005). As expected, blocking DC-SIGN resulted in defective zymosan uptake by NT-transfected moDCs, although zymosan uptake was unaffected by the addition of isotype controls (Figures S4A and S4B). Analysis performed on multiple donors confirmed our observations, and zymosan uptake was significantly impaired upon DC-SIGN blocking, indicating that DC-SIGN is the major receptor for zymosan in DCs (Figure S4C). These results demonstrate that Galectin-9 is an essential component in DC-SIGN receptor-mediated uptake by DCs.

Zymosan uptake experiments were also performed with murine bone marrow-derived dendritic cells (BMDCs) from WT and galectin-9-deficient (galectin9 ${ }^{-1-}$ ) mice. In line with human DCs, lack of Galectin9 in murine DCs resulted in defective phagocytic capacity, suggesting an evolutionarily conserved role for Galectin-9 in phagocytosis (Figures 3A and 3B). To investigate the effect of Galectin-9 in DC-mediated immunity against fungal pathogens, galectin-9-null mice were immunized with heat-inactivated Candida albicans and DC function analyzed (Figure 3C). Although we were not able to quantify phagocytosis in vivo, murine DCs lacking Galectin-9 displayed a significant decrease in cytokine secretion upon infection, indicating poor initiation of a proper immune response (Figures 3D-3G).

\section{Intracellular Galectin-9 Controls Plasma Membrane Structure in Dendritic Cells}

To examine whether the extra- or the intracellular pool of Galectin-9 was responsible for the defect in phagocytosis, moDCs were treated with lactose to remove extracellular galectins from the cell surface before being challenged with zymosan particles. Although lactose treatment effectively reduced the surface levels of Galectin-9 and Galectin-3 (Figures 4A and 4B), no effects on zymosan uptake were observed compared with untreated cells (Figure 4 C). Lactose was also added during zymosan incubation, and no differences in the phagocytic index of moDCs treated with lactose were observed, regardless of whether lactose was present during zymosan incubation (Figure S5). This indicates that the intracellular pool of Galectin-9 is responsible for particle uptake by moDCs and that particle binding and internalization are independent of Galectin-9-mediated interactions at the cell surface. These findings led us to hypothesize that Galectin-9 may interact with specific cytoskeleton components, which could alter the stability and/or the formation of phagosomes. To address this, Gal-9 KD and WT DCs were analyzed for their uptake ability upon treatment with cytochalasin D (cytD), which blocks actin polymerization by its binding to actin filaments. Addition of cytD resulted in a significant decrease of particle uptake in WT cells in contrast to Gal-9 KD moDCs that were not affected by cytD after challenging cells for 60 min (Figure 5A). Earlier time points were also analyzed, but DCs were still unable to take up any particles due to the inhibition of the actin cytoskeleton polymerization (Figures S6A and S6B). We excluded that this was due to a difference in particle binding between WT and Gal-9 KD cells (L. Querol Cano, unpublished data) or cell viability, which was not affected upon treatment with cytD (Figure S6C). Similar results were obtained when DCs were treated with increasing concentrations of cytD, confirming gal9 siRNA-transfected cells to be less sensitive to actin disruption than their WT counterparts (Figure S6D). To corroborate an impairment in the actin cytoskeleton upon Galectin-9 depletion, levels of F-actin were measured in WT and Gal-9 KD cells moDCs. A decrease of approximately $20 \%$ in the total levels of F-actin was seen in moDCs depleted for Galectin-9, confirming a specific effect for this lectin in the actin cytoskeleton arrangement (Figures 5B and 5C). 

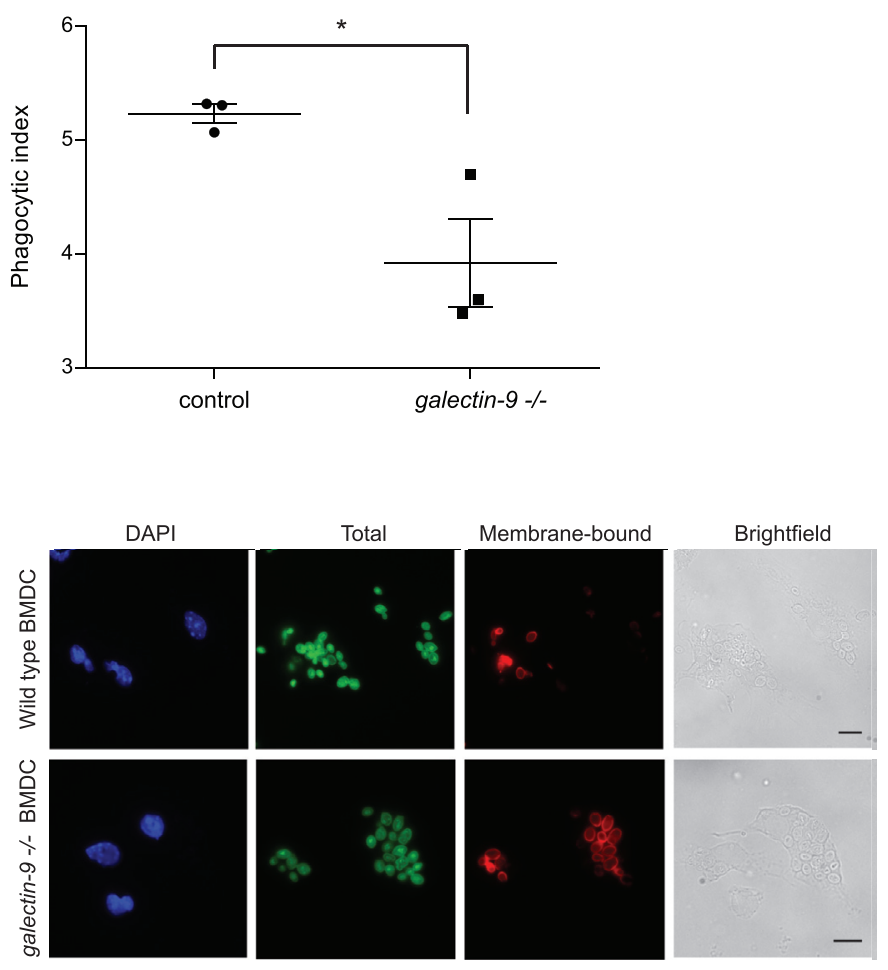

C

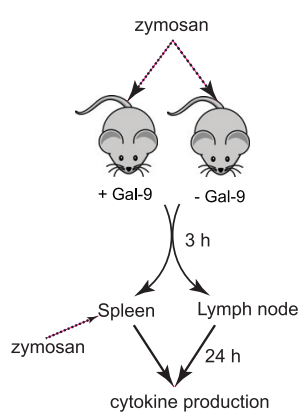

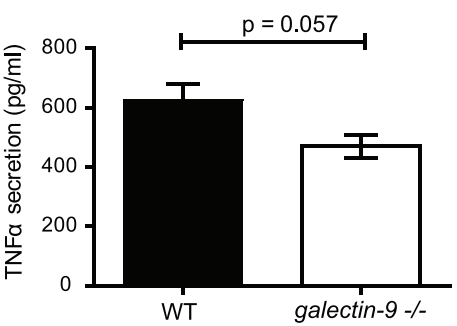

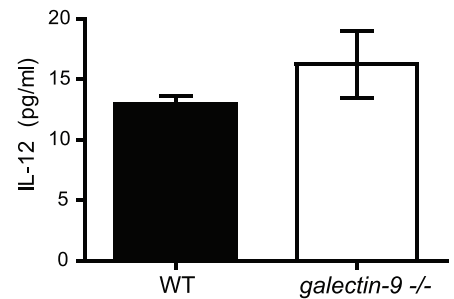

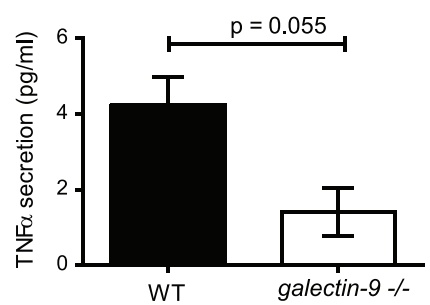

G

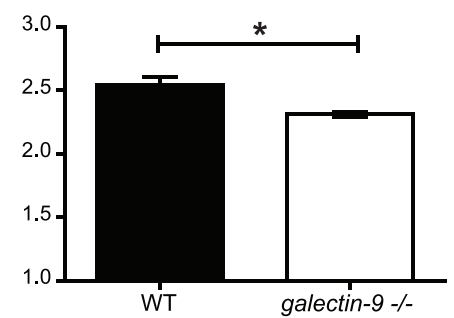

Figure 3. Galectin-9 Function in DC Is Conserved between Mouse and Human and Alters Dendritic Cell-Mediated Immune Responses In Vivo

(A) Bone marrow-derived dendritic cells (BMDCs) obtained from either wild-type (control) or galectin-9-null (galectin- $9^{-1}$ ) mice were seeded on coverslips, challenged with zymosan for $60 \mathrm{~min}$, and the phagocytic index calculated. Results show the mean phagocytic index value \pm SEM for three independent mice. Unpaired Student's $t$ test was conducted between wild-type and galectin- $9^{-1-}$ mice. ${ }^{*} \mathrm{p}<0.05$.

(B) Representative images from results shown in (A). Scale bar, $10 \mu \mathrm{m}$

(C-G) (C) Scheme depicting work protocol to assess anti-fungal immunity in galectin-9-null animals. Four wild-type (WT) and galectin-9 ${ }^{-/-}$mice were injected with heat-inactivated Candida albicans. Three hours after injection, lymph nodes and spleen were removed, single-cell suspensions made, and cells seeded onto 96-well plates. Spleen cell suspensions were re-stimulated 
Figure 3. Continued

with C. albicans, and $24 \mathrm{~h}$ after seeding cytokine secretion was measured in supernatants by ELISA. Tumor necrosis factor (TNF)- $\alpha$ production in spleen (D) or lymph node (E) samples. Interleukin (IL)-12 production in spleen (F) or lymph node $(G)$ samples. Graph shows the mean value \pm SEM for four animals. Unpaired Student's t test was conducted between WT and Gal9 KO cells. * $p<0.05$.

Experiments performed with galectin-9 ${ }^{-/-}$murine BMDCs confirmed this defect in cellular actin content (Figures 5D and 5E). Furthermore, confocal imaging showed that the percentage of F-actin-positive phagosomes was reduced upon Gal-9 KD in moDCs challenged with zymosan particles by approximately $40 \%$ (Figures 5F and 5G) in line with our previous observation (Figure 5B). These data suggest that depletion of Galectin-9 leads to reduced actin filament formation both under basal conditions and around phagosomes. To further verify Galectin-9 involvement in directly controlling the actin cytoskeleton, super-resolution laser scanning microscopy was performed on ventral plasma membrane sheets of moDCs. These studies demonstrated that Galectin-9 closely associates with the cortical actin cytoskeleton under basal conditions (Figure 6).

To unravel the mechanism underlying Galectin-9 function in plasma membrane integrity and structure, we exploited atomic force microscopy (AFM) to analyze the cellular stiffness of moDCs transfected with either NT or gal9 siRNA. Nanomechanical probing of the cells was achieved by obtaining a series of force-distance curves on selected points of the cell surface. A sharp non-functionalized cantilever with a radius of approximately $35 \mathrm{~nm}$ was brought into contact with a flat area of a single DC attached to a glass coverslip applying a mechanical force (Figure 7A). The use of a combined bright-field AFM setup allowed for accurately positioning the cantilever over specific areas of interest on the cell surface (Figure 7B). Analysis of the approach force-distance curves obtained for each point of interest allowed calculation of the cytoskeletal stiffness using the linearized Sneddon equation (Figure 7C). For this purpose, minimum and maximum fit boundaries (shown in blue) were defined respectively as $10 \%$ and $70 \%$ of the maximum force after baseline correction (Figure 7C). The portion of the curves that was used for fitting with the linearized model is shown in purple, and the separation distance that corresponds to this fit region is in the range of 200-600 nm (Figure 7C). Given that the thickness of the lipid bilayer is approximately $4 \mathrm{~nm}$ (Yokokawa et al., 2008), it is plausible to presume that the underlying cytoskeletal structures such as cortical actin and peripheral cytoplasm were also probed in our experiments. The mechanical characterization performed on DCs shows that moDCs lacking Galectin-9 have a decreased cytoskeletal rigidity compared with their WT counterparts (Figure 7D), in line with the defect in their cytoskeleton previously observed.

As it is well known that actin polymerization is mediated by small GTPases of the Rho family including Rac1 (Caron and Hall, 1998; May et al., 2000; Swanson, 2008; Norman et al., 1996), we investigated the effect of Galectin-9 depletion on Rac1 activation by specifically measuring its GTP-bound fraction using a G-LISA colorimetric assay. Incubation of control moDCs with zymosan particles resulted in a fast induction of Rac1-GTP activity already after 5-min stimulation (Figures $8 \mathrm{~A}$ and 8B), which was sustained in time (Figures $8 \mathrm{~A}$ and $8 \mathrm{C}$ ). Depletion of Galectin-9 abrogated Rac1 induction, and no increase in its GTP-bound form could be observed upon zymosan stimulation in moDCs transfected with gal9 siRNA at any of the time points analyzed (Figures 8A-8C). The recruitment of total Rac1 to nascent phagocytic cups was also impaired upon Gal-9 KD (Figures 8D-8F), suggesting that Galectin-9 promotes both Rac1 recruitment and activity on phagosomes.

Taken together, intracellular Galectin-9 controls plasma membrane structure via modulating Rac1 activity and actin polymerization, which underlies Galectin-9 requirement for phagocytosis in DCs.

\section{DISCUSSION}

Galectins have gained increasing interest for their role as extracellular organizers of plasma membrane components via glycan-mediated interactions. Nonetheless, their mechanism of action remains poorly understood, and in particular, their intracellular functions are ill-defined (Buschow et al., 2012). Here, we identified a previously unrecognized function for intracellular Galectin-9 in actin cytoskeleton reorganization and report a novel, functional interaction between Galectin-9 and the C-type lectin receptor DC-SIGN at the cytosol of DCs. Several members of the Galectin family are expressed in the cytosol, and some, such as Galectin-1 or Galectin-3 are predominantly intracellular proteins (Liu et al., 2002; 

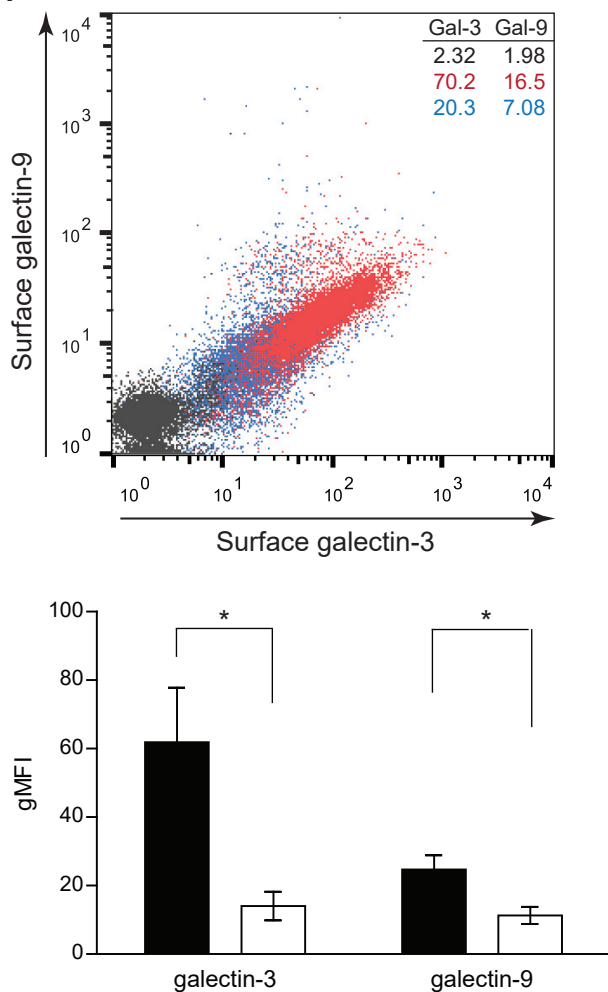

C

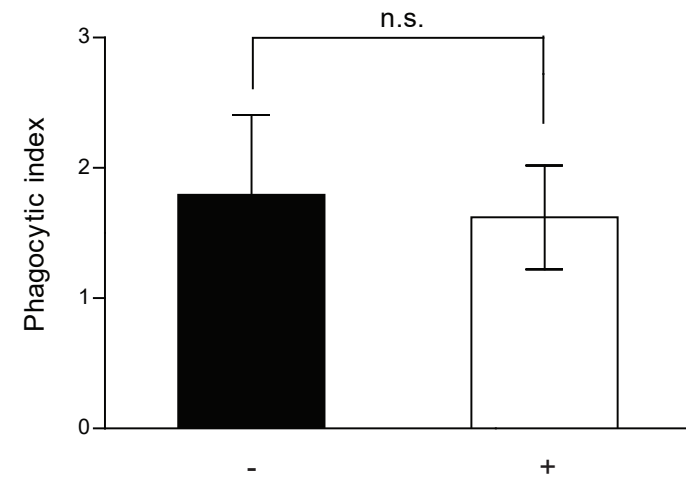

B
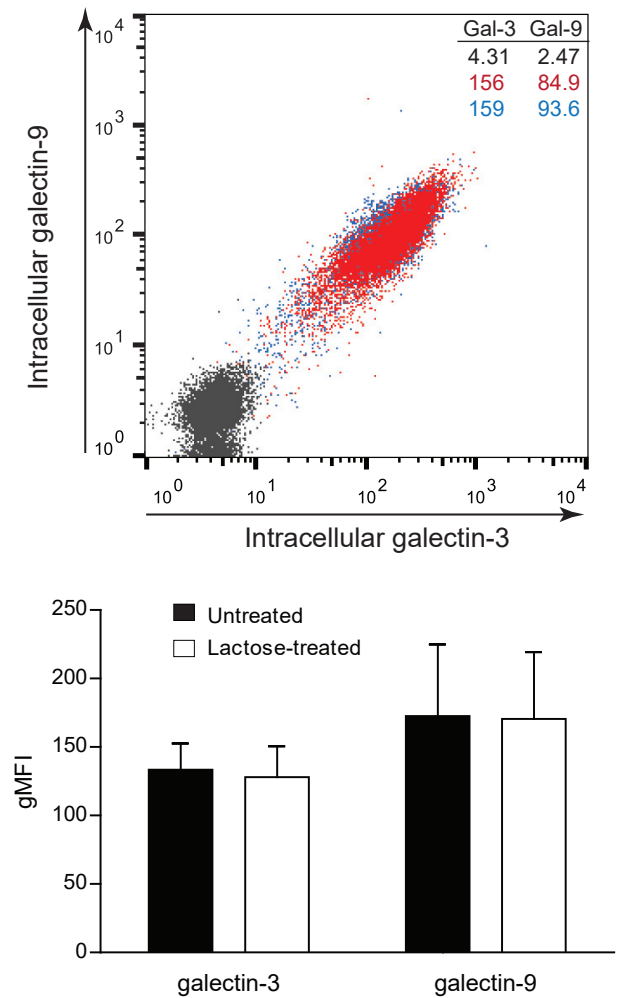

Figure 4. Intracellular Galectin-9 Is Responsible for Modulating Dendritic Cell Function

( $A$ and $B$ ) moDCs were treated with $35 \mathrm{mM}$ lactose for $48 \mathrm{~h}$, and removal of extracellular (A) but not intracellular (B) Galectin-9 and Galectin-3 expression was confirmed by flow cytometry. Red population, untreated cells; blue population, lactose-treated cells; black population, isotype control. Numbers in inset indicate gMFI. Panels depict representative results for one donor, and graphs show the mean phagocytic index \pm SEM for three independent donors. Unpaired Student's t test was conducted between untreated control and lactose-treated cells.

(C) Control or lactose-treated cells were challenged with zymosan for $60 \mathrm{~min}$. Cells were then fixed, stained, and the phagocytic index calculated. Graphs show the mean \pm SEM for three independent donors. Unpaired Student's t test was conducted between untreated control and lactose-treated cells. n.s.: $p>0.05,{ }^{\star} p<0.05$. See also Figure S5.

Wilson et al., 1989; Clerch et al., 1988; Hubert et al., 1995). Very little is known regarding the localization and function of cytoplasmic Galectin-9, although it has been implicated in protein folding and signal transduction (John and Mishra, 2016; Vasta et al., 2012). Our study now demonstrates that the large intracellular pool of Galectin-9 is responsible for the phagocytic capacity in DCs by modulating plasma 
$\mathbf{A}$

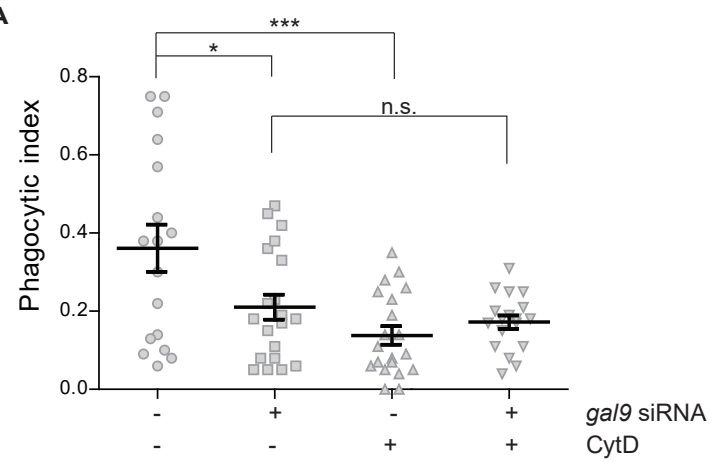

B

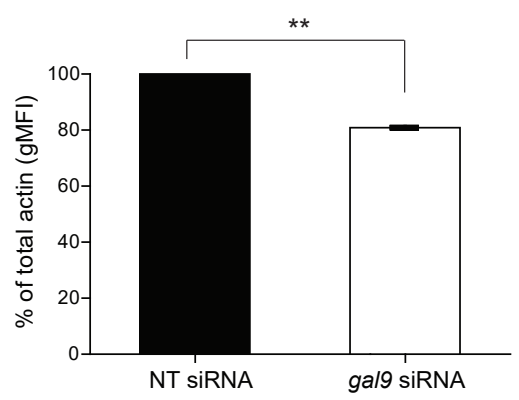

C

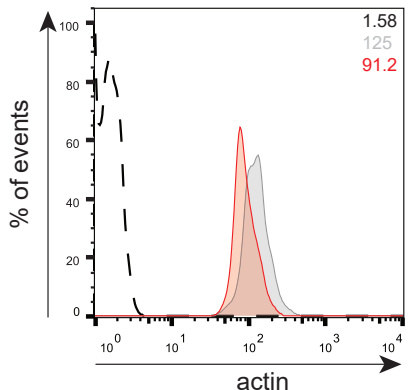

D

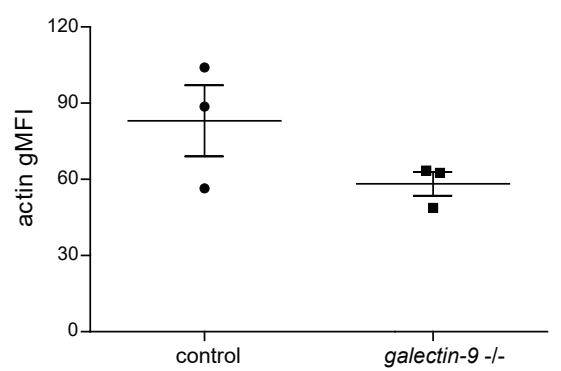

E

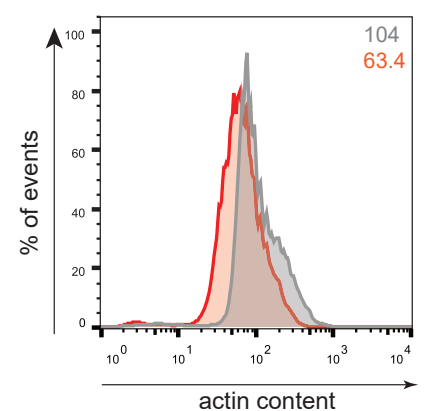

$\mathbf{F}$

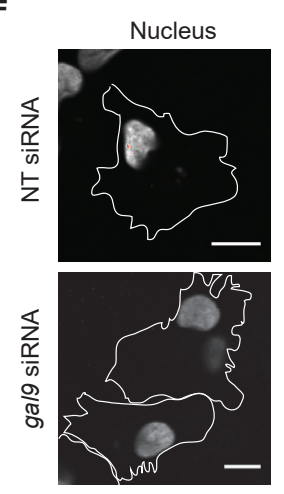

Zymosan
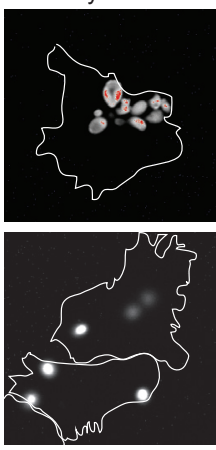

F-actin rings
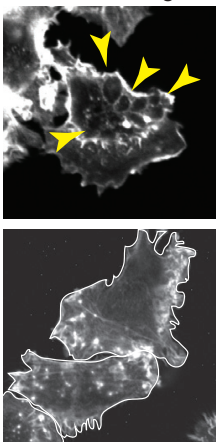

G

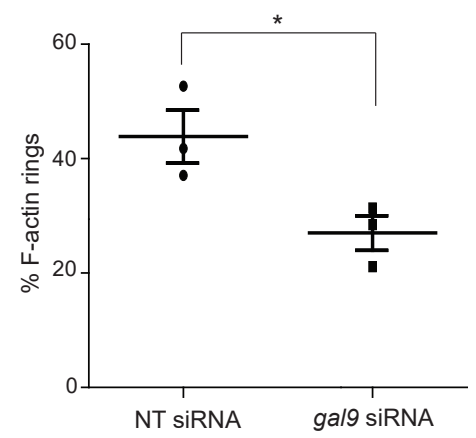

Figure 5. Galectin-9 Modulates Cellular Actin Cytoskeleton

(A) NT or gal9 siRNA-transfected moDCs were pretreated with $1.25 \mu \mathrm{g} / \mathrm{mL}$ cytochalasin D (cytD) for 10 min before being challenged with zymosan for $60 \mathrm{~min}$. Cells were then fixed, stained, and the phagocytic index calculated. Twenty frames were analyzed for each condition and donor. Data represent mean average phagocytic index \pm SEM for one representative donor out of three independent experiments. Unpaired Student's t test was conducted between NT and gal9 siRNA-transfected cells. 
Figure 5. Continued

(B) Actin levels were analyzed by flow cytometry in NT and ga/9 siRNA-transfected moDCs. Results are expressed as percent gMFI of gal9 siRNA-transfected cells relative to their NT control. Data represent mean average \% gMFI for three independent experiments \pm SEM. One-way t test was conducted.

(C) Representative histogram for actin expression after Galectin-9 knockdown. Gray area, NT siRNA-transfected moDCs; red area, gal9 siRNA-transfected moDCs; black dotted line, isotype control. Numbers in inset indicate gMFI.

(D) Actin levels of BMDC obtained from wild-type (control) or galectin-9 ${ }^{-1-}$ mice were analyzed by flow cytometry. Data represent mean average gMFI for three independent mice \pm SEM

(E) Representative histogram for actin expression. Gray line, control BMDCs; red line, galectin- $9^{-/-}$BMDCs. Numbers in inset indicate gMFI.

(F) Representative confocal images of F-actin rings in moDCs transfected as in (A) and challenged with zymosan particles for 15 min.

(G) Quantification of the percentage of F-actin-positive phagosomes of experiments shown in (F).

Data represent mean average \pm SEM. n.s.: $p>0.05,{ }^{*} p<0.05,{ }^{* \star} p<0.005,{ }^{* \star *} p<0.001$. See also Figure S6.

membrane structure, revealing a novel function for Galectins in cytoskeleton remodeling. This was observed in both human and murine cells, which indicates Galectin-9 as an evolutionarily conserved lectin required for maintaining the cortical cytoskeleton structure and function in DCs. Our data support a model in which Galectin-9 is essential for DC-SIGN-mediated phagocytosis, by (1) maintaining plasma membrane and cortical actin stiffness and (2) controlling receptor function (Figure 9). We identified that the underlying mechanism involves Galectin-9-dependent activation and recruitment of Rac1-GTP upon particle incubation, which triggers actin polymerization and the subsequent formation of phagocytic cups.

In line with this, our AFM studies demonstrate that Galectin-9-depleted cells have a less rigid plasma membrane and cortical cytoskeleton, rendering them unable to adequately modify their structure upon
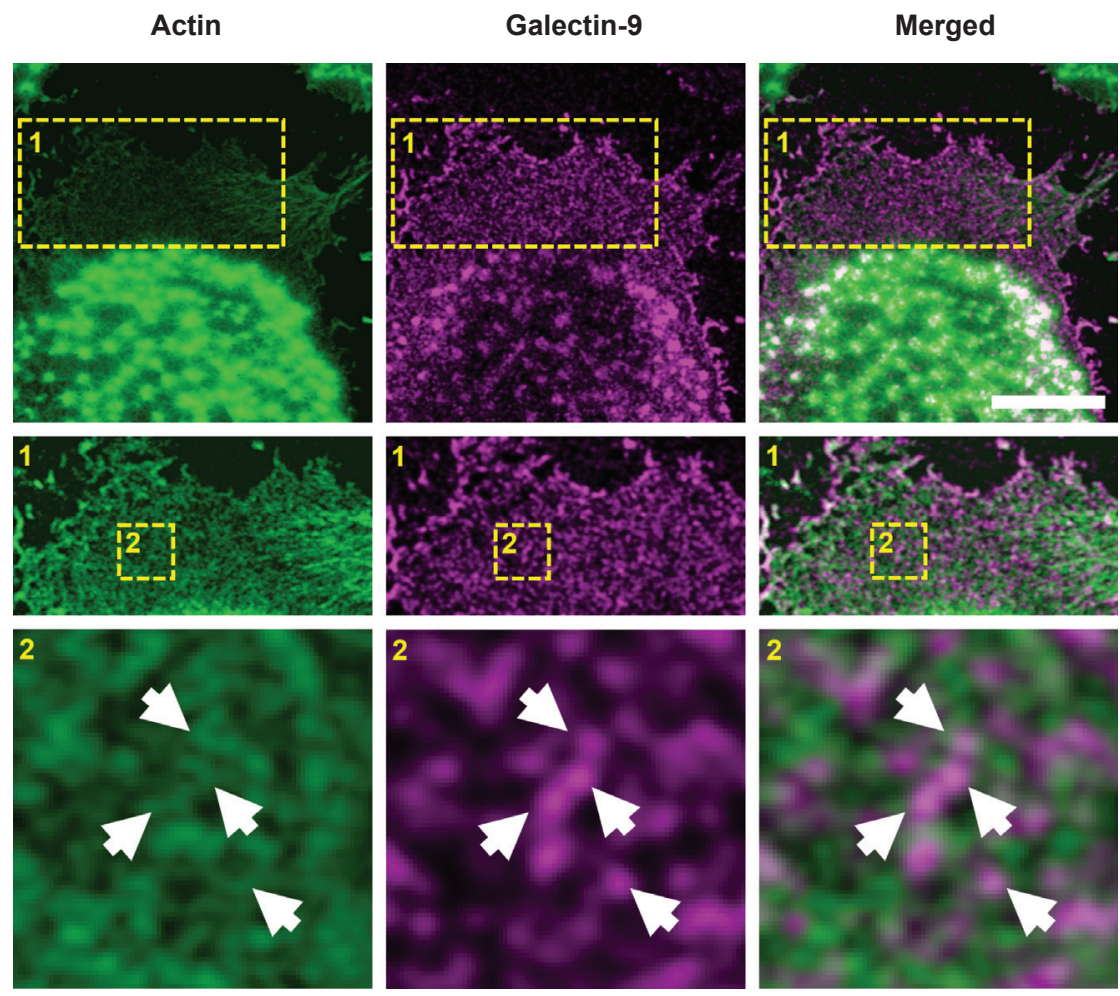

Figure 6. Galectin-9 Closely Associates with the Actin Cytoskeleton

Ventral plasma membrane sheets from day 5 moDCs were stained for actin and Galectin-9 and imaged with superresolution microscopy. A representative plasma membrane sheet out of four independent experiments is shown. Gamma correction (0.2) was applied to enhance the contrast of the actin image. Lower images: magnification of the area indicated in the upper images. Scale bar, $10 \mu \mathrm{m}$. Arrows indicate sites of Galectin-9 and actin colocalization. 
A

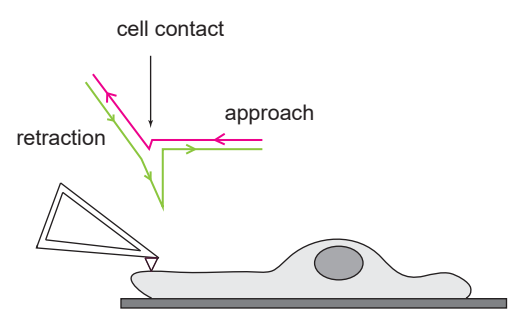

B

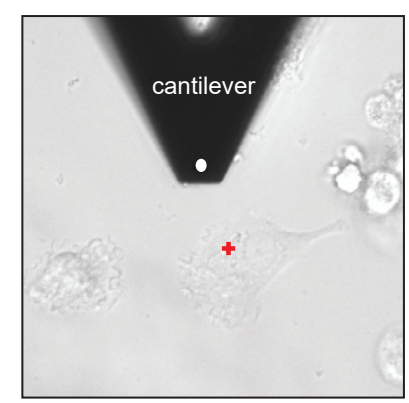

C

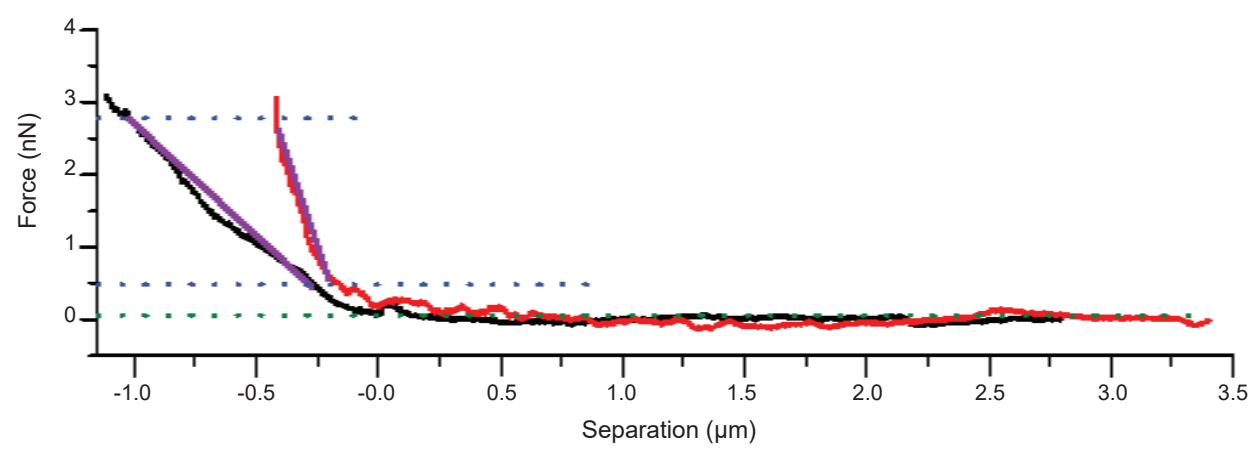

D

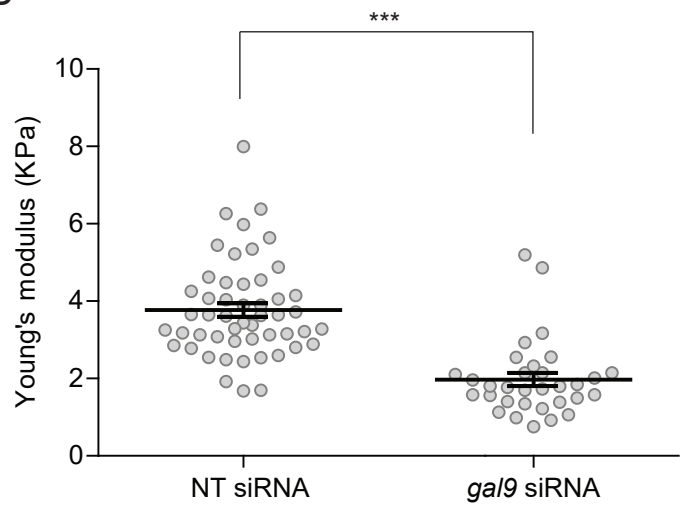

Figure 7. Galectin-9 Alters Cytoskeletal Membrane Rigidity

(A) Schematic AFM single-cell elasticity measurement setup showing an overview of the AFM cantilever in contact with the $D C$ and the cantilever movement used to measure the change in cantilever deflection.

(B) Optical image of gal9 siRNA-transfected moDCs obtained during the mechanical probing of the cell. White dot shows the position of the tip, and the red cross depicts the region of interest at the membrane that was indented with the cantilever.

(C) Representative force-distance curves obtained on gal9 siRNA-transfected (black) and NT siRNA (red) moDCs and curve-fitting approach to determine the Young's modulus of elasticity. Blue lines correspond to upper- and lower-fit boundaries ( $70 \%$ and $10 \%$ of the maximum force, respectively); purple lines show fitted portion of the curves used to calculate Young's modulus.

(D) Young's modulus of elasticity was calculated by fitting the force-distance curves indicated in (C). Data represent mean average Young's modulus of elasticity \pm SEM of three independent donors, and each data point shows the average value for three different locations for each moDC. Ten to thirty cells were analyzed for each donor in each independent experiment. Unpaired Student's $t$ test was conducted between NT and gal9 siRNAtransfected cells. ${ }^{\star \star \star} p<0.001$. 
A

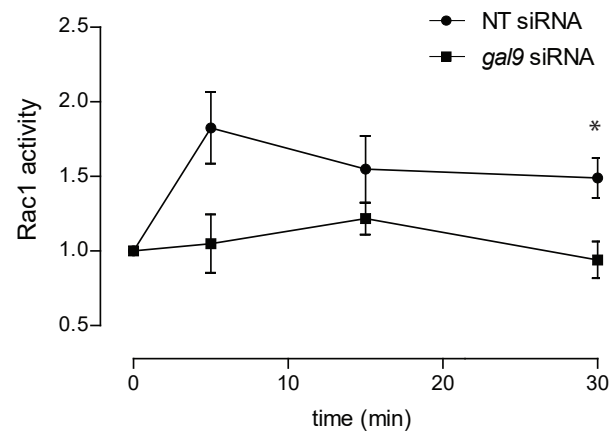

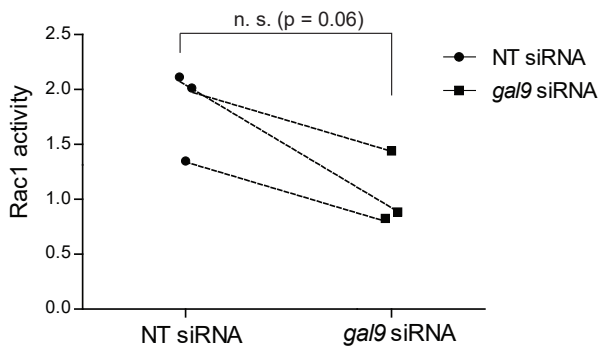

C

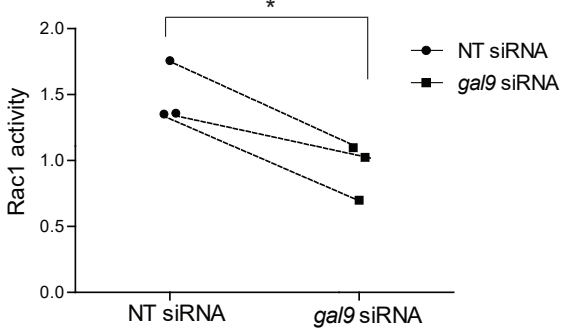

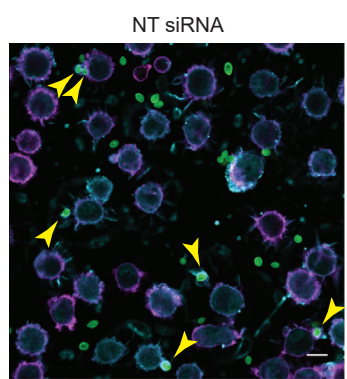

gal9 siRNA

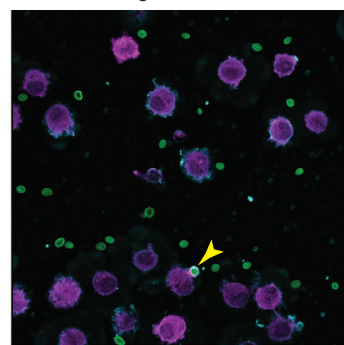

$\mathbf{E}$

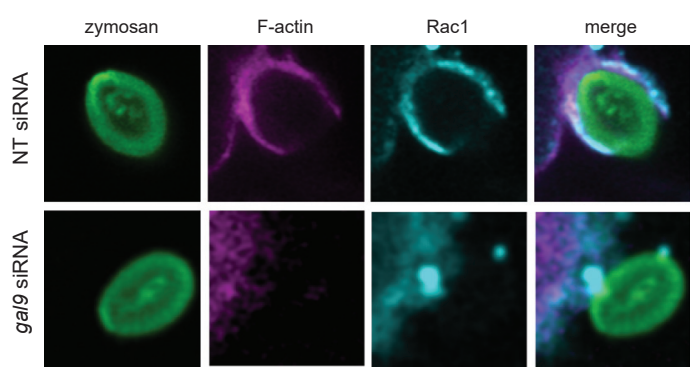

$\mathbf{F}$

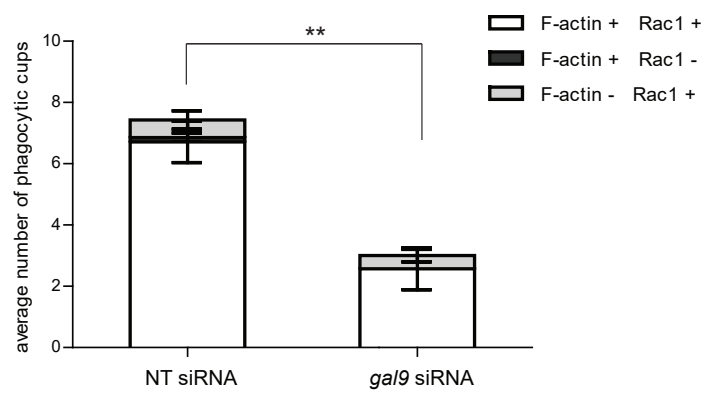

Figure 8. Galectin-9 Promotes Phagosomal Rac1 Activity

(A) NT and gal9 siRNA-transfected moDCs were challenged with zymosan particles for the indicated time points. After this time, cells were lysed, total protein was quantified, and Rac1-GTP activation was determined. Results are expressed as fold increase Rac1-GTP levels and relative to the unstimulated corresponding sample. Data represent mean average Rac1-GTP fold induction \pm SEM of three independent donors. Unpaired Student's t test was conducted between NT and gal9 siRNA-transfected cells.

(B and C) Each symbol represents one independent donor, and lines connect paired NT and gal9 siRNA-transfected moDCs after stimulation with zymosan for either $5 \mathrm{~min}(\mathrm{~B})$ or $30 \mathrm{~min}(\mathrm{C})$. 
Figure 8. Continued

(D) NT or gal9 siRNA-transfected moDCs were challenged with zymosan_FITC for 5 min before being stained for F-actin (magenta) and Rac1 (blue) and imaged with super-resolution microscopy. A representative confocal image out of 9 images is shown. Scale bar, $10 \mu \mathrm{m}$. Arrows indicate overlap between Rac1 and F-actin signal on phagocytic cups.

(E) Magnification of representative phagocytic cups in NT and gal9 siRNA-transfected moDCs treated as in (D). (F) Number of Rac1- and/or F-actin-positive phagocytic cups found on moDCs treated as in (D). Nine images containing between 20 and 30 cells were analyzed for each condition. Data represent mean average number of phagocytic cups \pm SEM. Unpaired Student's t test was conducted between NT and gal9 siRNA-transfected cells.

${ }^{*} \mathrm{p}<0.05 ;{ }^{* *} \mathrm{p}<0.01$; n.s $\mathrm{p}>0.05$

particle engulfment. Moreover, inhibition of actin polymerization did not affect the phagocytic ability of Gal-9 KD cells in contrast to WT cells. Although actin executes a pivotal function in phagocytosis, little is known regarding the mechanisms that govern F-actin recruitment to a nascent phagosome due to the lack of high-resolution data (Baranov et al., 2016). Our data support a new concept in which intracellular Galectin-9 is required for actin polymerization, directly controlling plasma membrane rigidity, by enhancing the activity of the actin-binding protein Rac1. In line with this, Galectin-1 has been recently shown to re-activate F-actin protein levels (Quinta et al., 2016). Similarly, intracellular Galectin-3 has been proved to enhance phagocytosis in macrophages by its interaction with F-actin in the phagocytic cups (Sano et al., 2003; Serizawa et al., 2015). Intracellular ligands have been proposed to bind Galectins through protein-protein interactions independent of carbohydrate-mediated recognition, although whether both proteins interact directly or through an intermediary molecule is not known (de Oliveira et al., 2015; Johannes et al., 2018; Shimura et al., 2004). Whether Galectin-9 function in our study is carbohydrate independent remains to be elucidated, but knockdown of Galectin-9 in the presence of other Galectins was sufficient to induce defects in actin polymerization and cellular rigidity in DCs. DC-SIGN is known to interact with actin and Lsp-1, an F-actin-interacting protein through its cytoplasmic tail (Smith et al., 2007), which likely allows for extracellular particle binding, plasma membrane deformation, and actin polymerization to occur simultaneously. Moreover, DC-SIGN signaling results in enhanced RhoAGTPase activity (den Dunnen et al., 2009; Hodges et al., 2007). Our data now support that depletion of intracellular Galectin-9 is sufficient to disrupt the cytosolic complex of DC-SIGN with actin-binding proteins, ultimately impairing cytoskeleton reorganization and causing a reduction in the cellular phagocytic capacity. We identified Galectin-9 as an integral component of the actin cytoskeleton as well as of the intracellular DC-SIGN-associated complex, and it is conceivable that Galectin-9 exerts its effects on the cytoskeleton remodeling by directly linking F-actin filaments, actin remodeling proteins, and DCSIGN in a multi-protein complex (Figure 9). Alternatively, Galectin-9 may connect DC-SIGN with other plasma membrane receptors known to associate with actin, such as CD44, which has been previously shown to interact with Galectin-9, as a component of DC-SIGN-directed phagosomes in DCs (Wu et al., 2014; Buschow et al., 2012).

Aside of its direct effects on DC-SIGN, we expect Galectin-9 depletion to have additional effects on the function of other lectin receptors involved in phagocytosis (mannose receptor, complement receptor 3, TLR2) (Sung et al., 1983; Xia et al., 1999). To date, extracellular Galectin-9 has been previously shown to interact with CD44, glucose transporter-2, immunoglobulin E, and Tim-3, a T cell type 1 membrane protein, known to be involved in T cell apoptosis and phagocytosis of apoptotic cells (Wu et al., 2014; Zhu et al., 2005). All these interactions, though, are carbohydrate dependent and mediated via glycan-lectin associations. To the best of our knowledge, no intracellular binding partners have been previously reported for Galectin-9.

The intracellular functions of Galectin-9 and particularly its role in phagocytosis have not been previously addressed, and our work is in line with Galectin-3 and Galectin-1 function in particle uptake, highlighting the broad importance of intracellular Galectins in enhancing cellular uptake (Farnworth et al., 2008; Sano et al., 2003; Barrionuevo et al., 2007; Caberoy et al., 2012; Linden et al., 2013; Quattroni et al., 2012). Furthermore, our studies with primary DCs demonstrate that disruption of glycan interactions solely alters particle uptake but not their binding to the cell membrane, which is in agreement with previous findings (Sano et al., 2003).

In summary, our work demonstrates a novel role for intracellular Galectin-9 in the regulation of the phagocytic activity through reorganization of the actin cytoskeleton that underlies plasma membrane rigidity in 
A wild type DCs

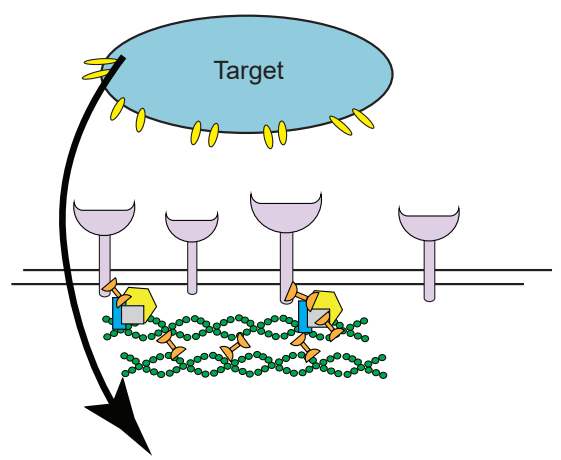

B gal9 knockdown DCs
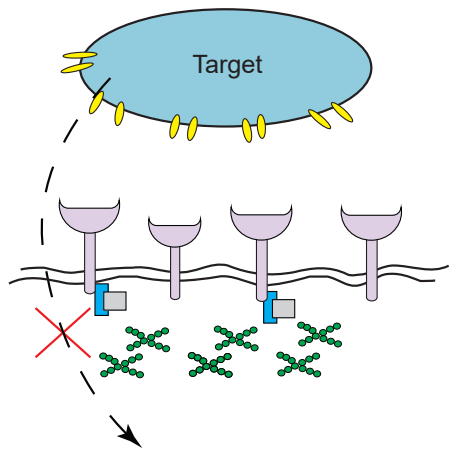

$\bigoplus$ C-type lectin receptor

$D=0$ Galectin-9
$\infty$ F-actin
O Pathogen-associated molecular pattern

Actin-associated proteins

Rac1-GTP

Figure 9. Model of the Role of Galectin-9 in Membrane Rigidity and Particle Uptake

(A) Intracellular Galectin-9 controls polymerization of cortical actin through interacting with C-type lectin phagocytic receptors and modulating Rac1 activity, which is essential for plasma membrane integrity and successful target uptake. (B) In the absence of Galectin-9, Rac1 activity is impaired, which results in abrogation of phagocytosis through decreased cortical actin levels and the subsequent loss of membrane rigidity.

DCs. Given the plethora of cellular biological processes Galectin-9 is involved in, this novel intracellular Galectin-9 mechanism of action contributes to the general understanding of plasma membrane structure and their implications in cell function.

\section{Limitations of the Study}

In this study we identified Galectin-9 as novel regulator of the actin cytoskeleton and plasma membrane structure in DCs. We have also defined and characterized the interaction and functional relationship between Galectin-9 and the phagocytic receptor DC-SIGN. Further work could be performed to confirm that both proteins interact intracellularly. Given the cytosolic localization and function of Galectin-9, a further in-depth characterization of the role Galectin-9 in governing the intracellular signaling pathway downstream of DC-SIGN would also be pertinent.

\section{METHODS}

All methods can be found in the accompanying Transparent Methods supplemental file.

\section{SUPPLEMENTAL INFORMATION}

Supplemental Information can be found online at https://doi.org/10.1016/j.isci.2019.11.019.

\section{ACKNOWLEDGMENTS}

We thank Sjoerd van Helvert and Roel Hammink for help with atomic force microscopy and Erik Jansen for help in preparing the yeast cells for the in vivo immunizations. This work is supported by the Dutch Cancer Society (Grant 11618, to L.Q.C.); A.B.v.S. is supported by the Netherlands Organisation for Scientific Research (NWO-ALW VIDI Grant 864.11.006), the Dutch Cancer Society (KUN2014-6845), and the European Research Council (ERC CoG 724281). C.G.F. is recipient of the Netherlands Organization for Scientific Research Spinoza Prize and ERC Adv Grant ARTimmune (834618). 


\section{AUTHOR CONTRIBUTIONS}

Conceptualization: L.Q.C. C.G.F., and A.B.v.S; Methodology and Investigation: L.Q.C., O.T., Y.D., S.D., A.v.D., S.I.B., B.J., and K.v.d.D. Resources: T.N. and M.H. Writing - Original draft: L.Q.C., A.C., C.G.F., and A.B.v.S. All authors read and provided input on the manuscript. Writing - Review and Editing: L.Q.C. and A.B.v.S. Funding Acquisition: L.Q.C., S.B., C.G.F., and A.B.v.S.

\section{DECLARATION OF INTERESTS}

The authors would like to declare the following competing interests: Drs. Niki and Hirashima are board members of GalPharma Co., Ltd. This does not alter the authors' adherence to all iScience policies on sharing data and materials.

Received: May 9, 2019

Revised: October 17, 2019

Accepted: November 11, 2019

Published: December 20, 2019

\section{REFERENCES}

Alvarez, D., Vollmann, E.H., and von Andrian, U.H. (2008). Mechanisms and consequences of dendritic cell migration. Immunity 29, 325-342.

Anderson, A.C., Anderson, D.E., Bregoli, L. Hastings, W.D., Kassam, N., Lei, C., Chandwaskar, R., Karman, J., Su, E.W.', Hirashima, M. et al. (2007). Promotion of tissue inflammation by the immune receptor Tim-3 expressed on innate immune cells. Science 318, 1141-1143.

Banchereau, J., Briere, F., Caux, C., Davoust, J., Lebecque, S., Liu, Y.J., Pulendran, B., and Palucka, K. (2000). Immunobiology of dendritic cells. Annu. Rev. Immunol. 18, 767-811.

Banchereau, J., and Steinman, R.M. (1998). Dendritic cells and the control of immunity. Nature 392, 245-252

Baranov, M.V., Revelo, N.H., Dingjan, I. Maraspini, R., Ter Beest, M., Honigmann, A., and van den Bogaart, G. (2016). SWAP70 organizes the actin cytoskeleton and is essential for phagocytosis. Cell Rep. 17, 1518-1531.

Barrionuevo, P., Beigier-Bompadre, M., Ilarregui, J.M. Toscano M.A Bianco G.A Isturiz, MA. and Rabinovich, G.A. (2007). A novel function for galectin-1 at the crossroad of innate and adaptive immunity: galectin-1 regulates monocyte/ macrophage physiology through a nonapoptotic ERK-dependent pathway. J. Immunol. 178, 436-445.

Bi, S., Earl, L.A., Jacobs, L., and Baum, L.G. (2008). Structural features of galectin-9 and galectin-1 that determine distinct $T$ cell death pathways. J. Biol. Chem. 283, 12248-12258.

Buschow, S.I., Lasonder, E., Szklarczyk, R., Oud M.M., de Vries, I.J., and Figdor, C.G. (2012) Unraveling the human dendritic cell phagosome proteome by organellar enrichment ranking.

J. Proteomics 75, 1547-1562.

Caberoy, N.B., Alvarado, G., Bigcas, J.L., and Li, W. (2012). Galectin-3 is a new MerTK-specific eatme signal. J. Cell. Physiol. 227, 401-407.

Cambi, A., Beeren, I., Joosten, B., Fransen, J.A and Figdor, C.G. (2009). The C-type lectin DCSIGN internalizes soluble antigens and HIV-1 virions via a clathrin-dependent mechanism. Eur. J. Immunol. 39, 1923-1928.

Cambi, A., Gijzen, K., de Vries, L.J., Torensma, R., Joosten, B. Adema, G.J. Netea, M.G., Kullberg B.J., Romani, L., and Figdor, C.G. (2003). The Ctype lectin DC-SIGN (CD209) is an antigenuptake receptor for Candida albicans on dendritic cells. Eur. J. Immunol. 33, 532-538.

Cao, A., Allugmani, N., Buhari, F.H.M., Wasim, L., Smith L.K Quaile, A.T Shannon, M. Hakim, Z Furmli, H., Owen, D.M., et al. (2018). Galectin-9 binds IgM-BCR to regulate $B$ cell signaling. Nat. Commun. 9, 3288

Caron, E., and Hall, A. (1998). Identification of two distinct mechanisms of phagocytosis controlled by different Rho GTPases. Science 282, 17171721

Clerch, L.B., Whitney, P., Hass, M., Brew, K., Miller, T., Werner, R., and Massaro, D. (1988) Sequence of a full-length cDNA for rat lung betagalactoside-binding protein: primary and secondary structure of the lectin. Biochemistry 27 692-699.

Curciarello, R., Steele, A., Cooper, D. MacDonald, T.T., Kruidenier, L., and Kudo, T. (2014). The role of Galectin-1 and Galectin-3 in the mucosal immune response to Citrobacter rodentium infection. PLoS One 9, e107933.

Dai, S.Y., Nakagawa, R., Itoh, A., Murakami, H., Kashio, Y., Abe, H., Katoh, S., Kontani, K., Kihara, M., Zhang, S.L., et al. (2005). Galectin-9 induces maturation of human monocyte-derived dendritic cells. J. Immunol. 175, 2974-2981.

de Kivit, S., Kostadinova, A.I., Kerperien, J. Ayechu Muruzabal, V., Morgan, M.E., Knippels, L.M.J., Kraneveld, A.D., Garssen, J., and Willemsen, L.E.M. (2017). Galectin-9 produced by intestinal epithelial cells enhances aldehyde dehydrogenase activity in dendritic cells in a PI3K- and p38-dependent manner. J. Innate Immun. 9, 609-620.

de la Rosa, G., Yanez-Mo, M., Samaneigo, R., Serrano-Gomez, D. Martinez-Munoz, L. Fernandez-Ruiz, E., Longo, N., Sanchez-Madrid, F., Corbi, A.L., and Sanchez-Mateos, P. (2005).
Regulated recruitment of DC-SIGN to cell-cell contact regions during zymosan-induced human dendritic cell aggregation. J. Leukoc. Biol. 77, 699-709

de Oliveira, F.L., Gatto, M., Bassi, N., Luisetto, R., Ghirardello, A., Punzi, L., and Doria, A. (2015). Galectin-3 in autoimmunity and autoimmune diseases. Exp. Biol. Med. (Maywood) 240, 10191028 .

den Dunnen, J., Gringhuis, S.I., and Geijtenbeek, T.B. (2009). Innate signaling by the C-type lectin DC-SIGN dictates immune responses. Cancer Immunol. Immunother. 58, 1149-1157.

Elola, M.T., Blidner, A.G., Ferragut, F., Bracalente, C., and Rabinovich, G.A. (2015). Assembly, organization and regulation of cell-surface receptors by lectin-glycan complexes. Biochem. J. $469,1-16$

Farnworth, S.L., Henderson, N.C., Mackinnon, A.C., Atkinson, K.M., Wilkinson, T., Dhaliwal, K. Hayashi, K., Simpson, A.J., Rossi, A.G., Haslett, C., and Sethi, T. (2008). Galectin-3 reduces the severity of pneumococcal pneumonia by augmenting neutrophil function. Am. J. Pathol. 172, 395-405.

Geijtenbeek, T.B., Torensma, R., van Vliet, S.J., van Duijnhoven, G.C., Adema, G.J., van Kooyk, Y. and Figdor, C.G. (2000). Identification of DCSIGN, a novel dendritic cell-specific ICAM-3 receptor that supports primary immune responses. Cell 100, 575-585.

Giovannone, N., Liang, J., Antonopoulos, A. Geddes Sweeney, J., King, S.L., Pochebit, S.M. Bhattacharyya, N., Lee, G.S., Dell, A., Widlund, H.R., et al. (2018). Galectin-9 suppresses B cell receptor signaling and is regulated by branching of N-glycans. Nat. Commun. 9, 3287

Heinsbroek, S.E., Taylor, P.R., Martinez, F.O., Martinez-Pomares, L., Brown, G.D., and Gordon, S. (2008). Stage-specific sampling by pattern recognition receptors during Candida albicans phagocytosis. PLoS Pathog. 4, e1000218.

Heusschen, R., Griffioen, A.W., and Thijssen, V.L. (2013). Galectin-9 in tumor biology: a jack of 
multiple trades. Biochim. Biophys. Acta 1836, 177-185.

Heuze, M.L., Vargas, P., Chabaud, M., le Berre, M., Liu, Y.J., Collin, O., Solanes, P., Voituriez, R. Piel, M., and Lennon-Dumenil, A.M. (2013). Migration of dendritic cells: physical principles, molecular mechanisms, and functional implications. Immunol. Rev. 256, 240-254.

Hodges, A., Sharrocks, K., Edelmann, M., Baban, D., Moris, A., Schwartz, O., Drakesmith, H., Davies, K., Kessler, B., McMichael, A., and Simmons, A. (2007). Activation of the lectin DCSIGN induces an immature dendritic cell phenotype triggering Rho-GTPase activity required for HIV-1 replication. Nat. Immunol. 8, 569-577.

Hsu, D.K., Yang, R.Y., Saegusa, J., and Liu, F.T. (2015a). Analysis of the intracellular role of galectins in cell growth and apoptosis. Methods Mol. Biol. 1207, 451-463.

Hsu, Y.L., Wang, M.Y., Ho, L.J., Huang, C.Y., and Lai, J.H. (2015b). Up-regulation of galectin-9 induces cell migration in human dendritic cells infected with dengue virus. J. Cell. Mol. Med. 19, 1065-1076.

Hubert, M., Wang, S.Y., Wang, J.L., Seve, A.P., and Hubert, J. (1995). Intranuclear distribution of galectin-3 in mouse 3T3 fibroblasts: comparative analyses by immunofluorescence and immunoelectron microscopy. Exp. Cell Res. 220, 397-406.

Johannes, L., Jacob, R., and Leffler, H. (2018). Galectins at a glance. J. Cell Sci. 131, https://doi. org/10.1242/jcs.208884.

John, S., and Mishra, R. (2016). Galectin-9: from cell biology to complex disease dynamics. J. Biosci. 41, 507-534.

Jost, S. Moreno-Nieves, U.Y., Garcia-Beltran W.F., Rands, K., Reardon, J., Toth, I., PiechockaTrocha, A., Altfeld, M., and Addo, M.M. (2013). Dysregulated Tim-3 expression on natural killer cells is associated with increased Galectin-9 levels in HIV-1 infection. Retrovirology 10, 74.

Lajoie, P., Goetz, J.G., Dennis, J.W., and Nabi, I.R. (2009). Lattices, rafts, and scaffolds: domain regulation of receptor signaling at the plasma membrane. J. Cell Biol. 185, 381-385.

Lajoie, P., Partridge, E.A. Guay, G., Goetz, J.G. Pawling, J., Lagana, A., Joshi, B., Dennis, J.W., and Nabi, I.R. (2007). Plasma membrane domain organization regulates EGFR signaling in tumor cells. J. Cell Biol. 179, 341-356.

Leskela, S., Serrano, A., de la Fuente, H., Rodriguez-Munoz, A. Ramos-Levi, A Sampedro-Nunez, M., Sanchez-Madrid, F., Gonzalez-Amaro, R., and Marazuela, M. (2015). Graves' disease is associated with a defective expression of the immune regulatory molecule galectin-9 in antigen-presenting dendritic cells. PLoS One 10 e0123938.

Linden, J.R., Kunkel, D., Laforce-Nesbitt, S.S., and Bliss, J.M. (2013). The role of galectin-3 in phagocytosis of Candida albicans and Candida parapsilosis by human neutrophils. Cell. Microbiol. 15, 1127-1142.

Liu, F.T., Patterson, R.J., and Wang, J.L. (2002) intracellular functions of galectins. Biochim. Biophys. Acta 1572, 263-273

Liu, F.T., and Rabinovich, G.A. (2005). Galectins as modulators of tumour progression. Nat. Rev. Cancer 5, 29-41.

Liu, P. Ridilla, M., Patel, P. Betts, L. Gallichotte E., Shahidi, L., Thompson, N.L., and Jacobson, K. (2017). Beyond attachment: roles of DC-SIGN in dengue virus infection. Traffic 18, 218-231.

Manzo, C., Torreno-Pina, J.A., Joosten, B. Reinieren-Beeren, I., Gualda, E.J., Loza-Alvarez, P. Figdor, C.G., Garcia-Parajo, M.F., and Cambi, A. (2012). The neck region of the C-type lectin DC-SIGN regulates its surface spatiotemporal rganization and virus-binding capacity on antigen-presenting cells. J. Biol. Chem. 287, 38946-38955.

May, R.C., Caron, E., Hall, A., and Machesky, L.M (2000). Involvement of the Arp2/3 complex in phagocytosis mediated by FcgammaR or CR3 Nat. Cell Biol. 2, 246-248.

Nabi, I.R., Shankar, J., and Dennis, J.W. (2015) The galectin lattice at a glance. J. Cell Sci. 128 2213-2219.

Norman, J.C. Price, L.S, Ridley, A.J., and Koffer A. (1996). The small GTP-binding proteins, Rac and Rho, regulate cytoskeletal organization and exocytosis in mast cells by parallel pathways. Mol. Biol. Cell 7, 1429-1442.

Quattroni, P., Li, Y., Lucchesi, D., Lucas, S., Hood D.W., Herrmann, M., Gabius, H.J., Tang, C.M., and Exley, R.M. (2012). Galectin-3 binds Neisseria meningitidis and increases interaction with phagocytic cells. Cell. Microbiol. 14, 1657-1675.

Quinta, H.R., Wilson, C., Blidner, A.G., Gonzalez Billault, C., Pasquini, L.A., Rabinovich, G.A., and Pasquini, J.M. (2016). Ligand-mediated Galectin1 endocytosis prevents intraneural $\mathrm{H} 2 \mathrm{O} 2$ production promoting $\mathrm{F}$-actin dynamics reactivation and axonal re-growth. Exp. Neurol. 283, 165-178.

Rabinovich, G.A., and Toscano, M.A. (2009). Turning 'sweet' on immunity: galectin-glycan interactions in immune tolerance and inflammation. Nat. Rev. Immunol. 9, 338-352.

Sano, H., Hsu, D.K., Apgar, J.R., Yu, L., Sharma, B.B., Kuwabara, I., Izui, S., and Liu, F.T. (2003). Critical role of galectin-3 in phagocytosis by macrophages. J. Clin. Invest. 112, 389-397.

Savina, A., and Amigorena, S. (2007)

Phagocytosis and antigen presentation in dendritic cells. Immunol. Rev. 219, 143-156.

Serizawa, N., Tian, J., Fukada, H., Baghy, K., Scott, F., Chen, X., Kiss, Z., Olson, K., Hsu, D., Liu, F.T. et al. (2015). Galectin 3 regulates HCC cell invasion by RhoA and MLCK activation. Lab. Invest. 95, 1145-1156.

Shimura, T., Takenaka, Y., Tsutsumi, S., Hogan, V. Kikuchi, A., and Raz, A. (2004). Galectin-3, a novel binding partner of beta-catenin. Cancer Res. 64 6363-6367.

Smith, A.L., Ganesh, L., Leung, K., Jongstra-Bilen. J. Jongstra, J., and Nabel, G.J. (2007). Leukocytespecific protein 1 interacts with DC-SIGN and mediates transport of HIV to the proteasome in dendritic cells. J. Exp. Med. 204, 421-430.

Sundblad, V., Morosi, L.G., Geffner, J.R., and Rabinovich, G.A. (2017). Galectin-1: a jack-of-alltrades in the resolution of acute and chronic inflammation. J. Immunol. 199, 3721-3730.

Sung, S.S., Nelson, R.S., and Silverstein, S.C (1983). Yeast mannans inhibit binding and phagocytosis of zymosan by mouse peritoneal macrophages. J. Cell Biol. 96, 160-166.

Swanson, J.A. (2008). Shaping cups into phagosomes and macropinosomes. Nat. Rev. Mol. Cell Biol. 9, 639-649.

Tacken, P.J., de Vries, I.J., Giizen, K., Joosten, B., Wu, D., Rother, R.P., Faas, S.J., Punt, C.J., Torensma, R., Adema, G.J., et al. (2005). Effective induction of naive and recall $T$-cell responses by targeting antigen to human dendritic cells via a humanized anti-DC-SIGN antibody. Blood 106, $1278-1285$.

Thiemann, S., and Baum, L.G. (2016). Galectins and immune responses-just how do they do those things they do? Annu. Rev. Immunol. 34 243-264.

Vasta, G.R., Ahmed, H., Nita-Lazar, M., Banerjee, A., Pasek, M., Shridhar, S., Guha, P., and Fernandez-Robledo, J.A. (2012). Galectins as self/ non-self recognition receptors in innate and adaptive immunity: an unresolved paradox. Front. Immunol. 3, 199

Wilson, T.J., Firth, M.N., Powell, J.T., and Harrison, F.L. (1989). The sequence of the mouse $14 \mathrm{kDa}$ beta-galactoside-binding lectin and evidence for its synthesis on free cytoplasmic ribosomes. Biochem. J. 261, 847-852.

Wu, C., Thalhamer, T., Franca, R.F., Xiao, S., Wang, C., Hotta, C., Zhu, C., Hirashima, M. Anderson, A.C., and Kuchroo, V.K. (2014) Galectin-9-CD44 interaction enhances stability and function of adaptive regulatory $T$ cells. Immunity 41, 270-282.

Xia, Y., Vetvicka, V., Yan, J., Hanikyrova, M. Mayadas, T., and Ross, G.D. (1999). The betaglucan-binding lectin site of mouse CR3 (CD11b/ CD18) and its function in generating a primed state of the receptor that mediates cytotoxic activation in response to iC3b-opsonized target cells. J. Immunol. 162, 2281-2290.

Yokokawa, M., Takeyasu, K., and Yoshimura, S.H. (2008). Mechanical properties of plasma membrane and nuclear envelope measured by scanning probe microscope. J. Microsc. 232, 82-90.

Zhu, C., Anderson, A.C., Schubart, A., Xiong, H Imitola, J., Khoury, S.J., Zheng, X.X., Strom, T.B. and Kuchroo, V.K. (2005). The Tim-3 ligand galectin-9 negatively regulates $T$ helper type 1 immunity. Nat. Immunol. 6, 1245-1252. 
ISCI, Volume 22

Supplemental Information

Intracellular Galectin-9 Controls

Dendritic Cell Function by Maintaining

Plasma Membrane Rigidity

Laia Querol Cano, Oya Tagit, Yusuf Dolen, Anne van Duffelen, Shannon Dieltjes, Sonja I. Buschow, Toshiro Niki, Mitsuomi Hirashima, Ben Joosten, Koen van den Dries, Alessandra Cambi, Carl G. Figdor, and Annemiek B. van Spriel 
Figure S1.

A.

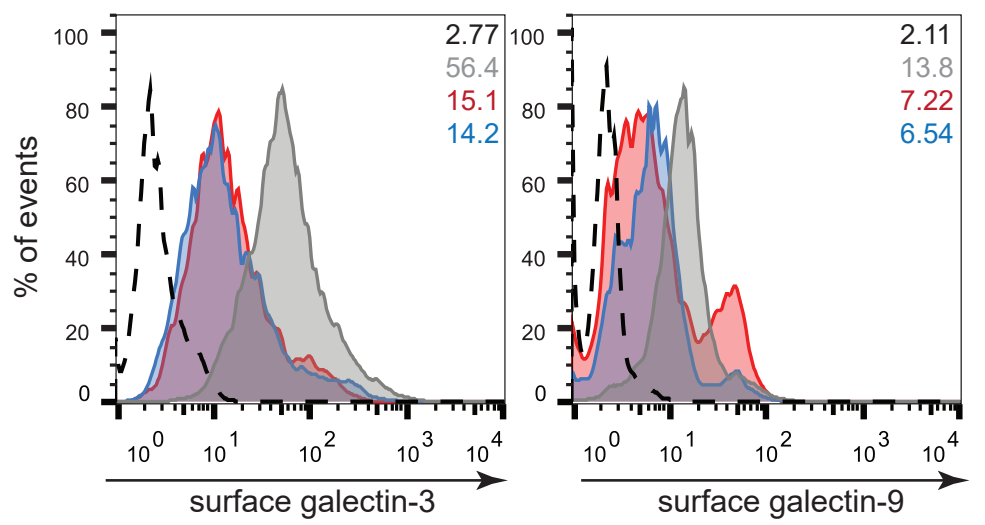

B.
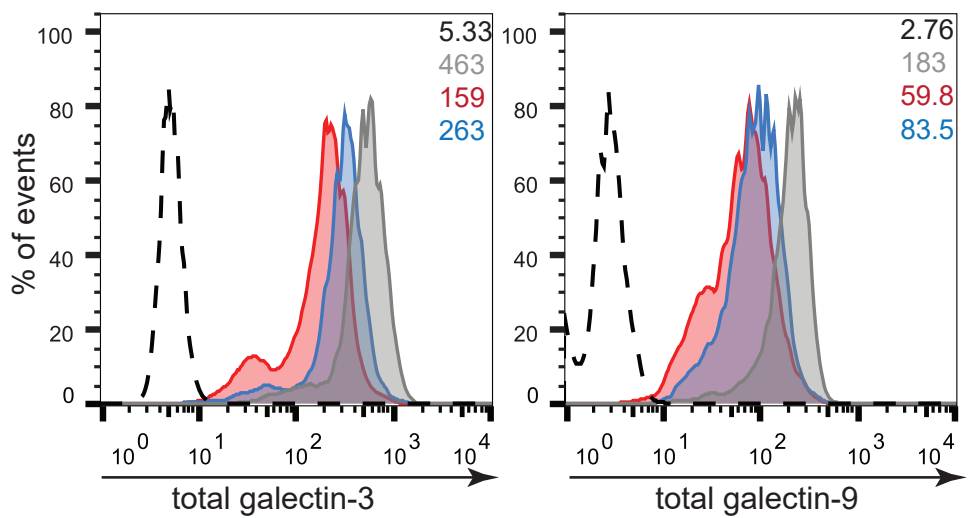

c.

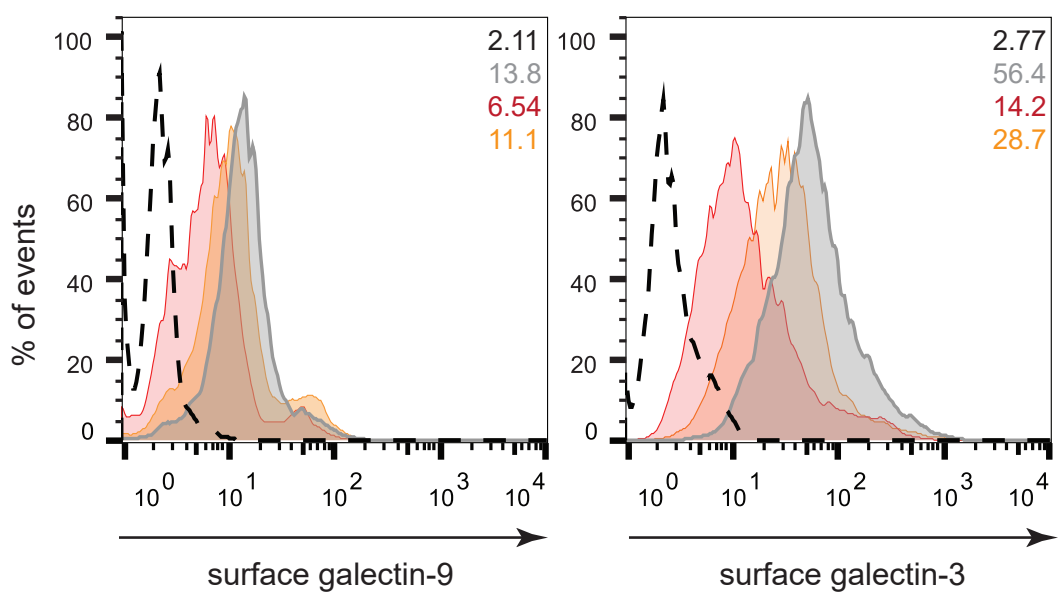


B.

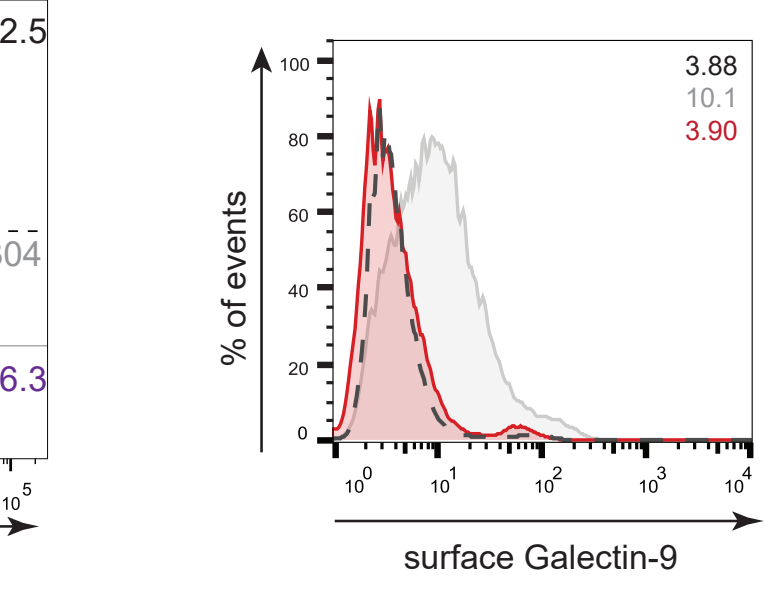

D.

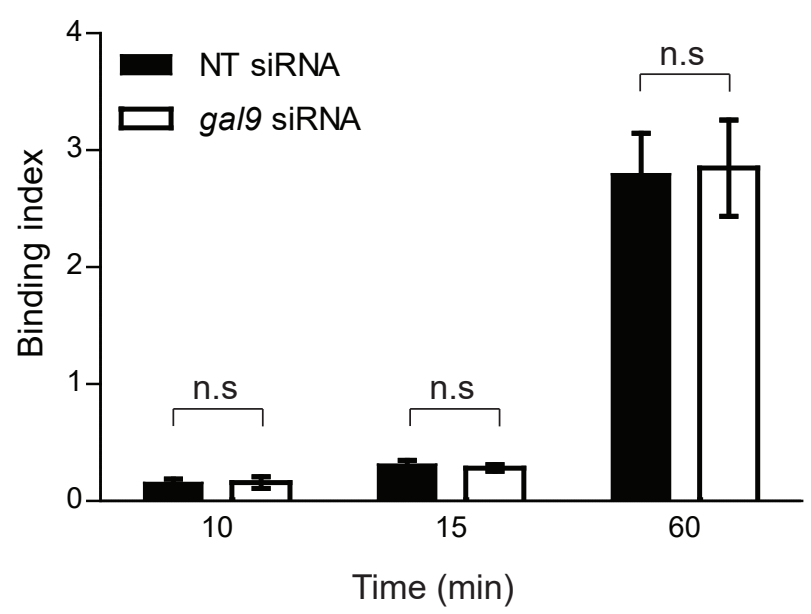

E.

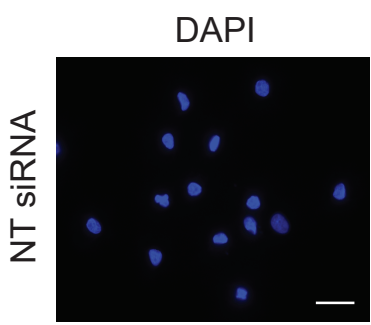

Total

membrane-bound
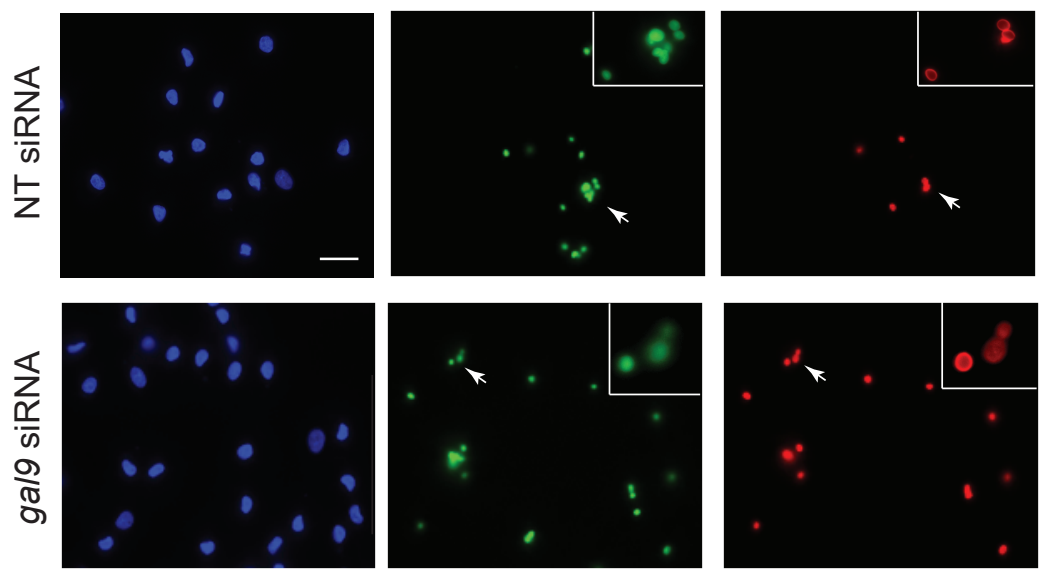

A.

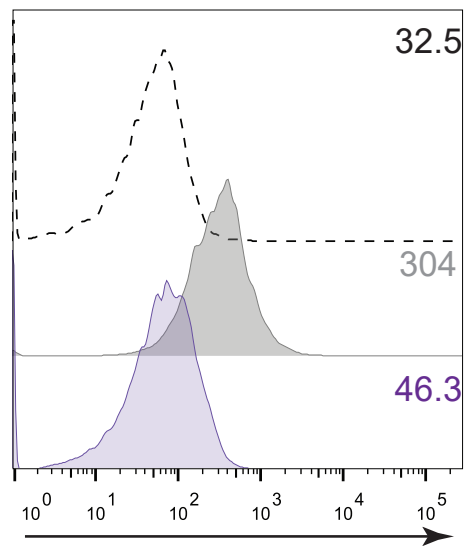

surface Galectin-9
C.

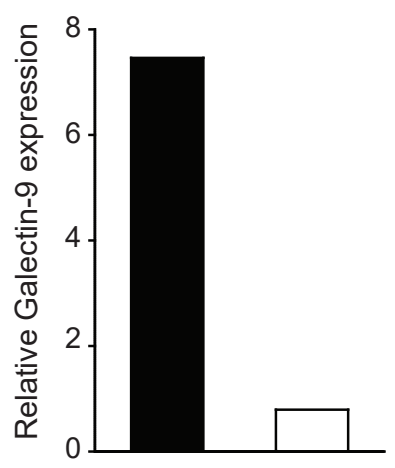

Galectin-9

Tubulin

NT SiRNA

gal9 siRNA

\section{Figure S2.}

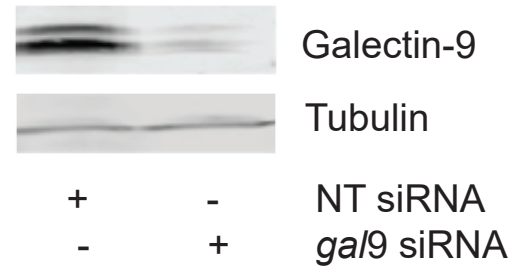




\section{Figure S3.}

A.

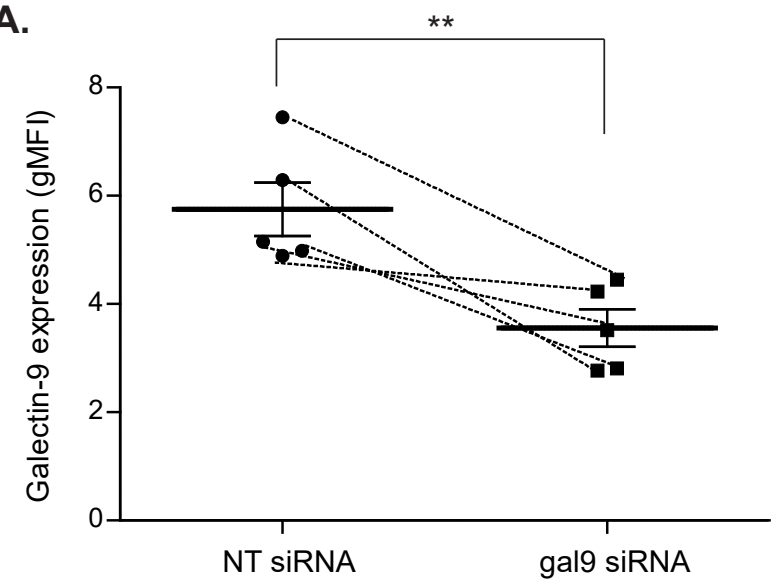

c.

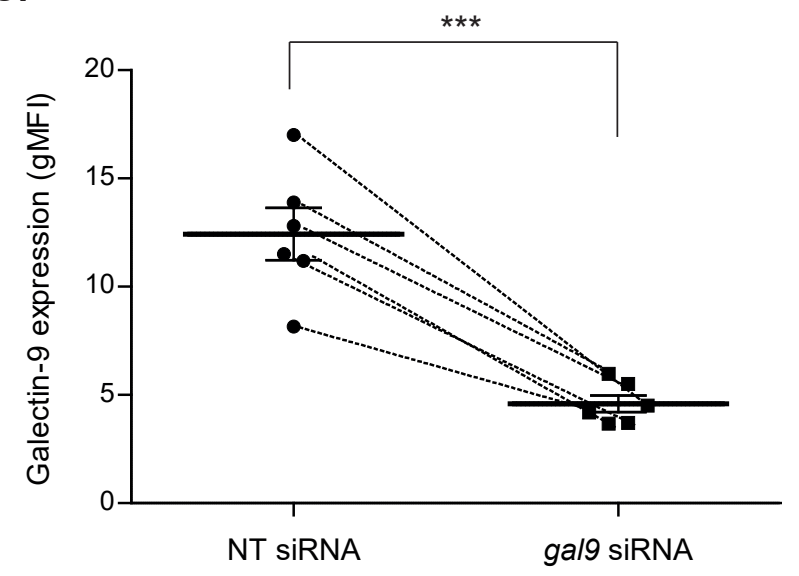

E.

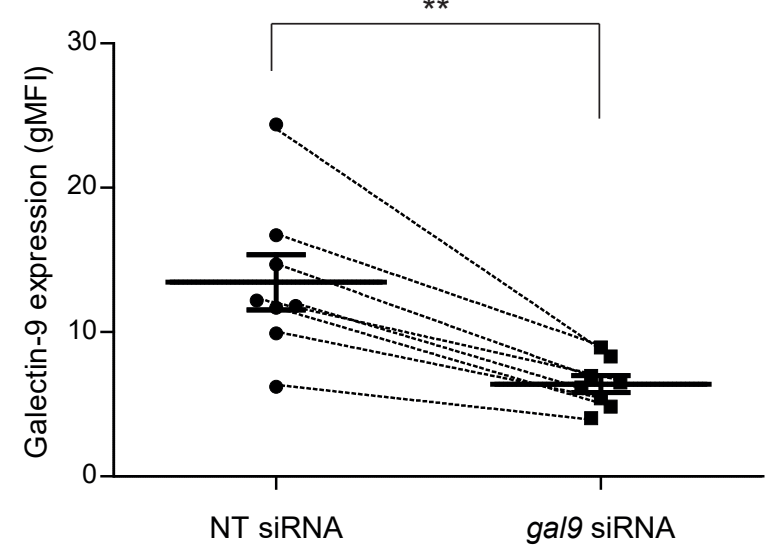

G.

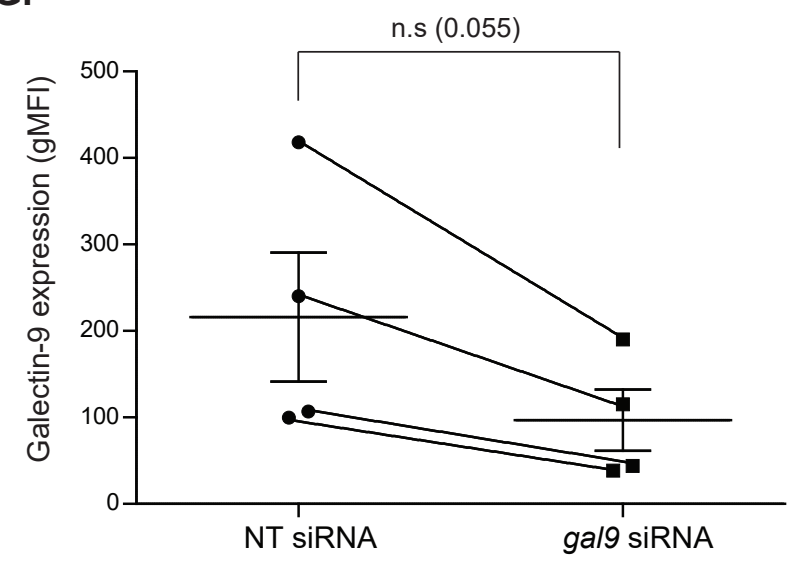

B. n.s.

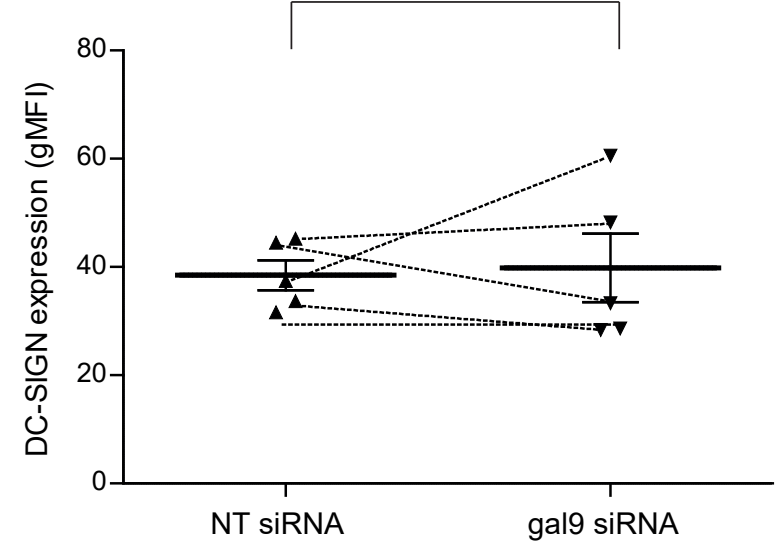

D.

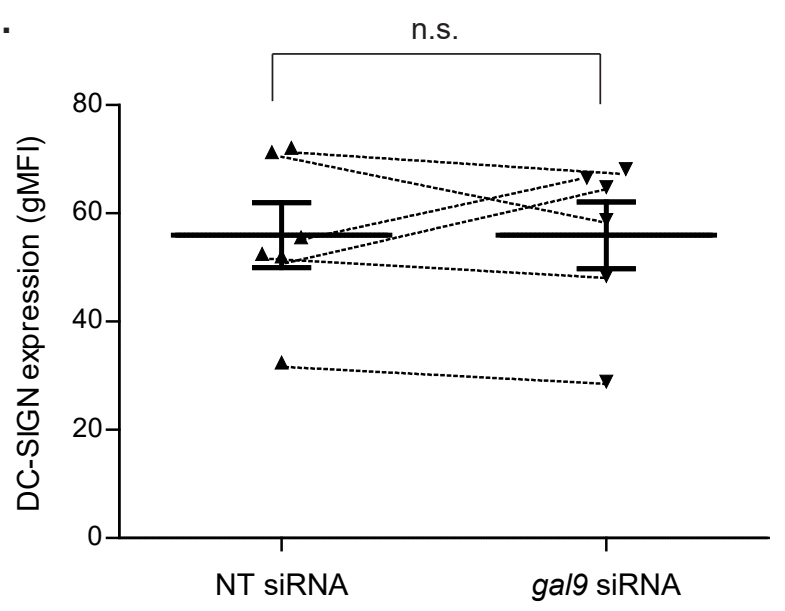

F.

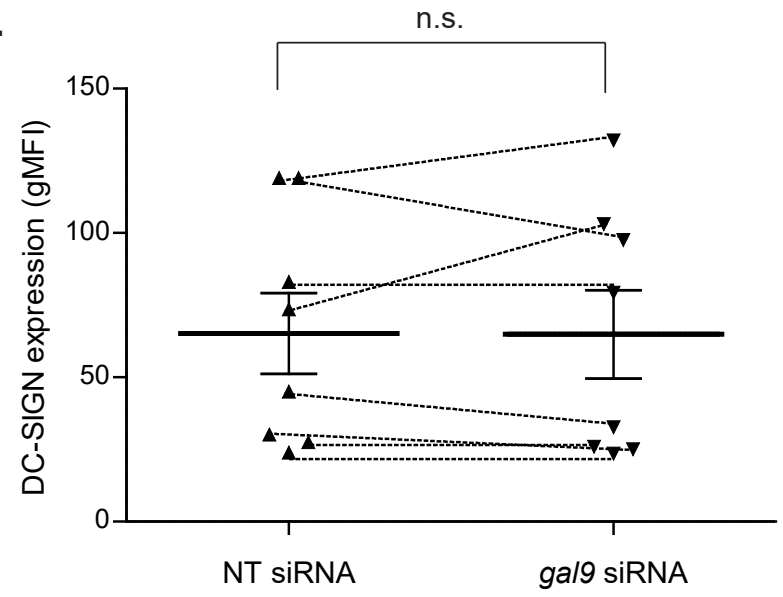

H.

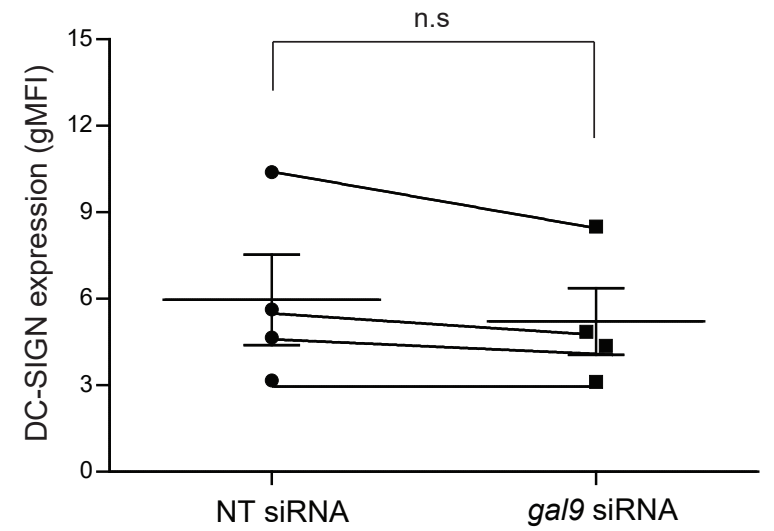


Figure S4.

A.

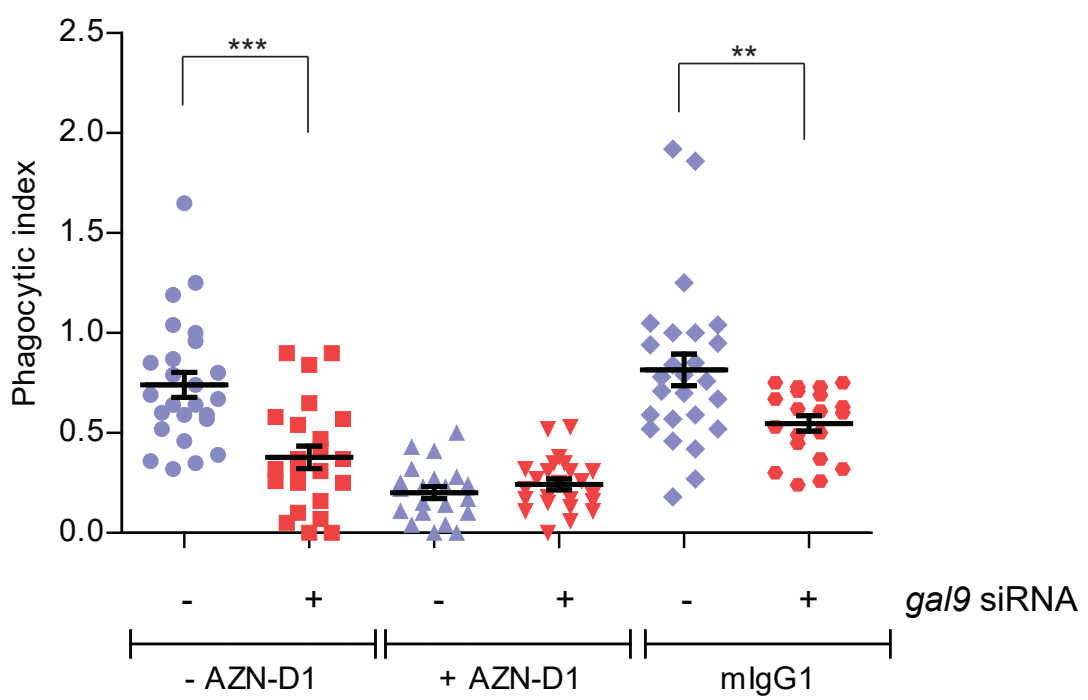

B.

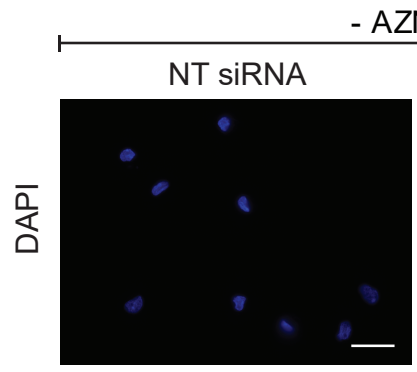

AZN-D1
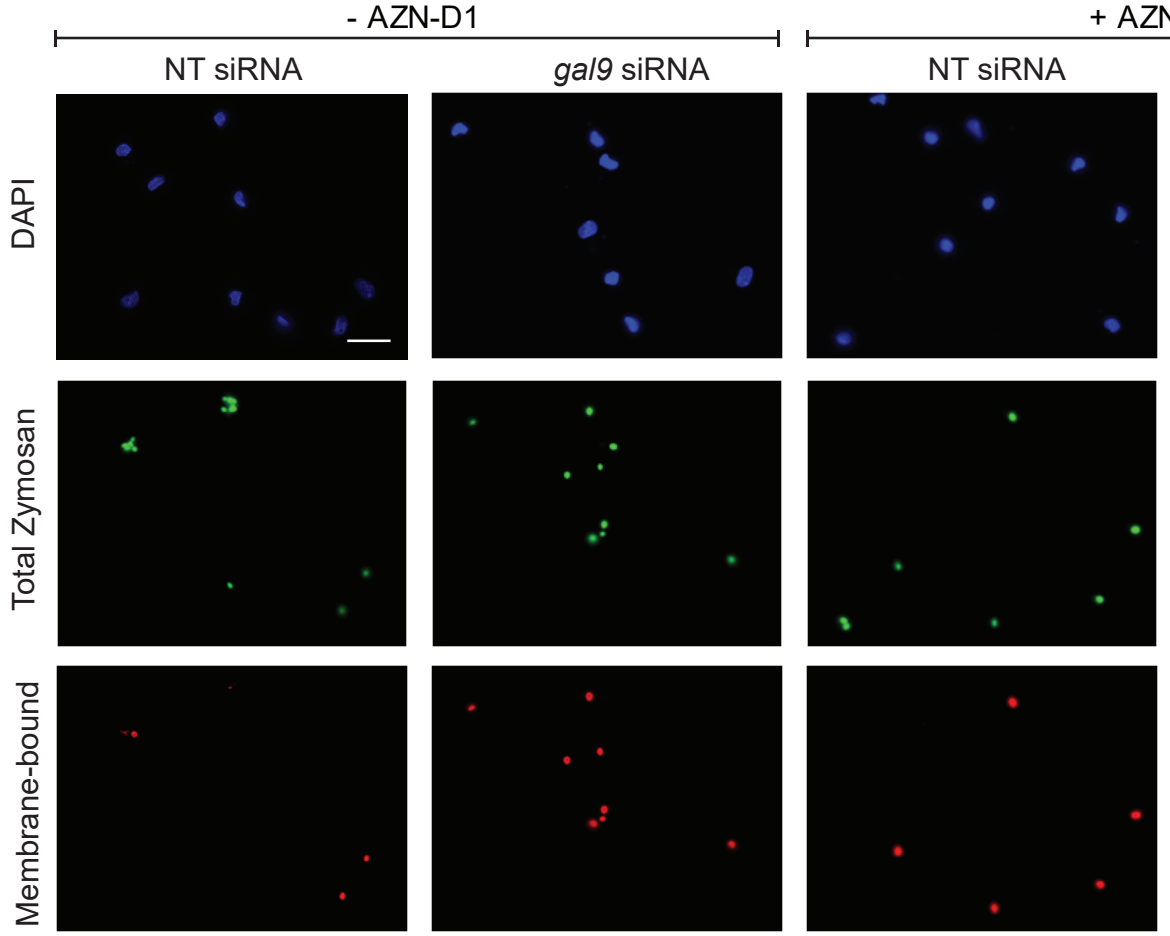

AZN-D1
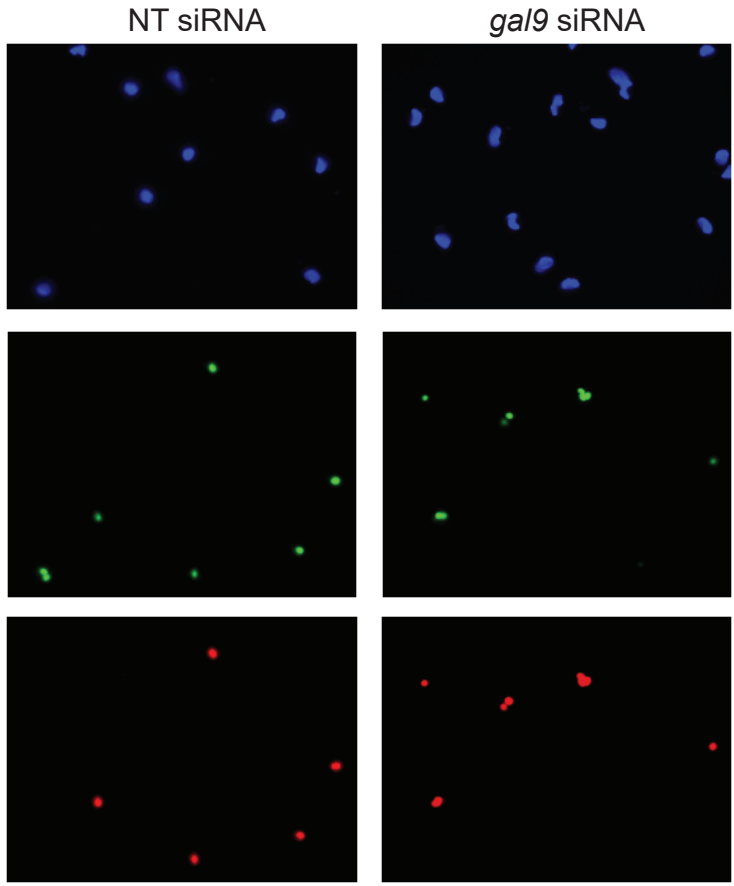

c.

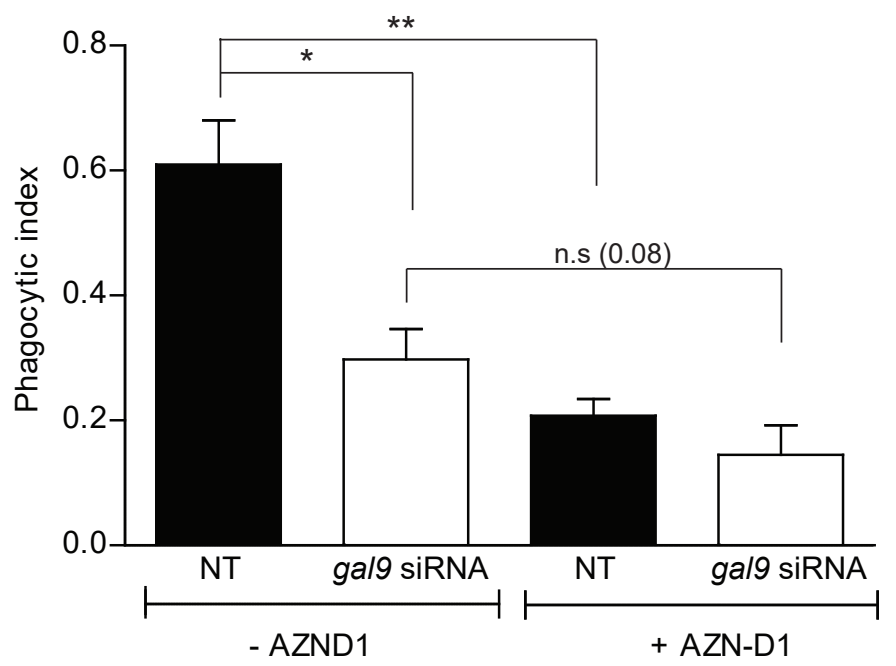


Figure S5.

A.

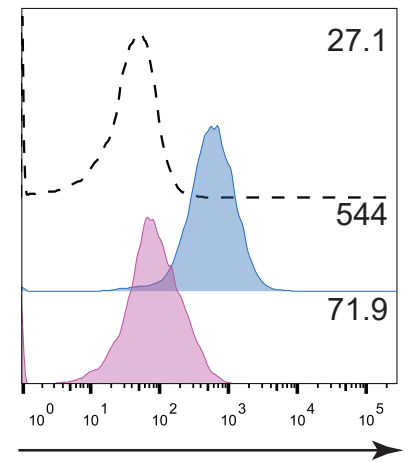

Galectin-3

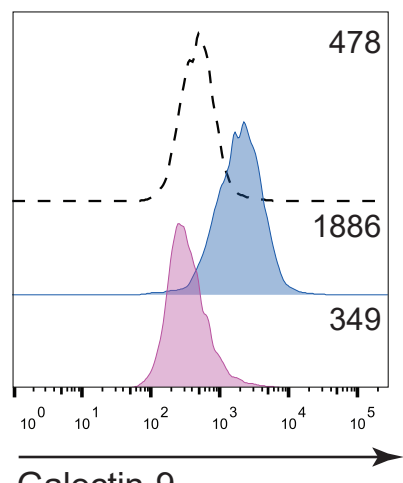

Galectin-9

B.
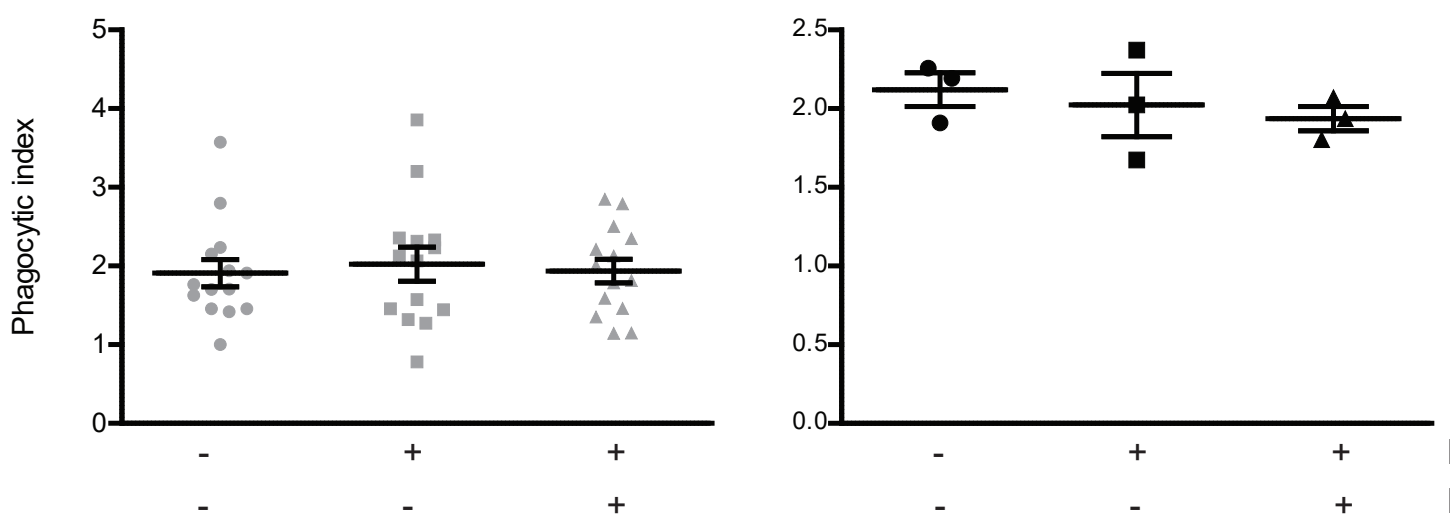

lactose during pre-treatment lactose during zymosan uptake 
Figure S6.

A.

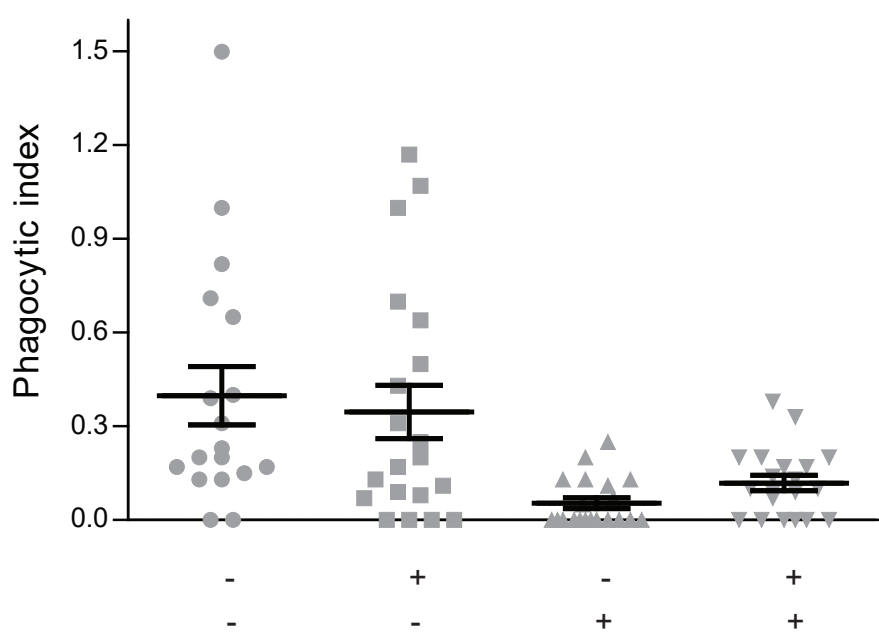

C.

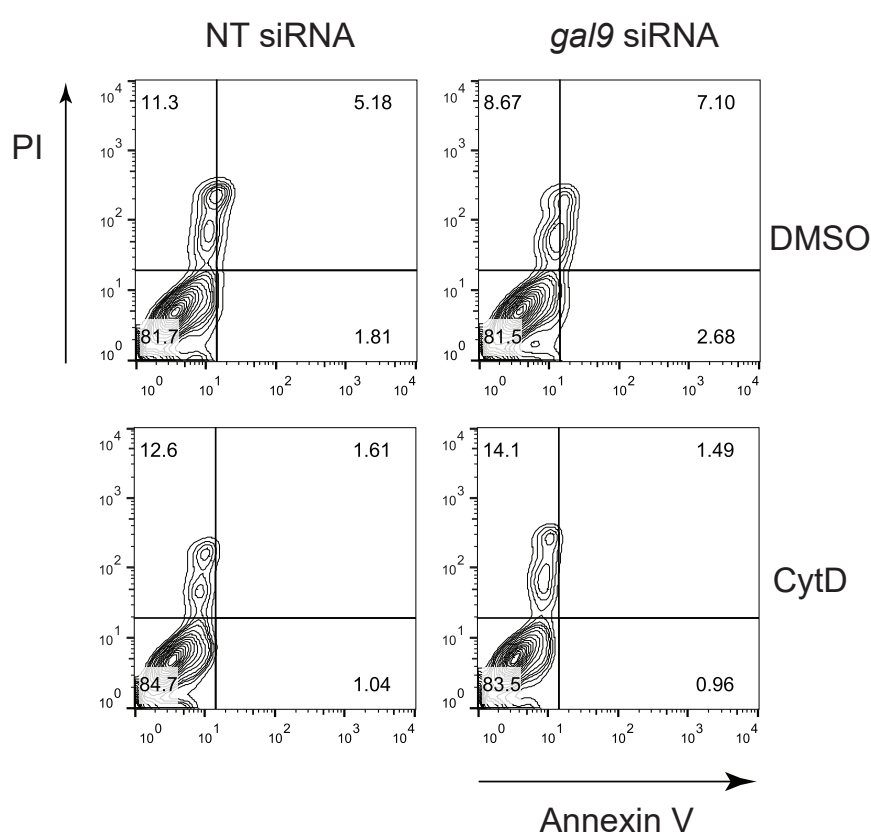

B.

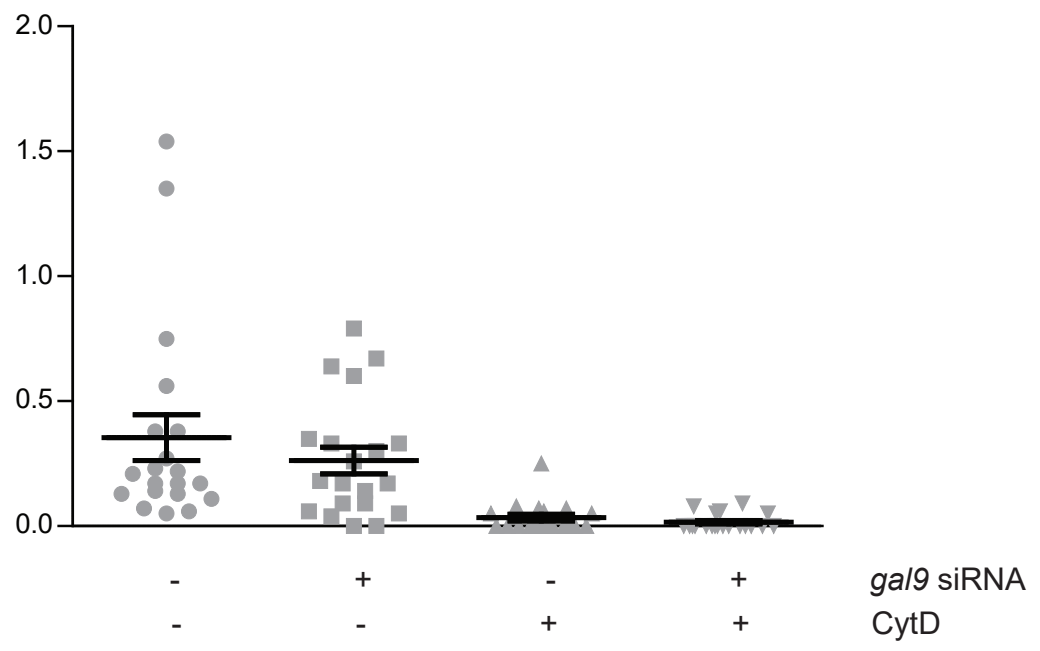

D.

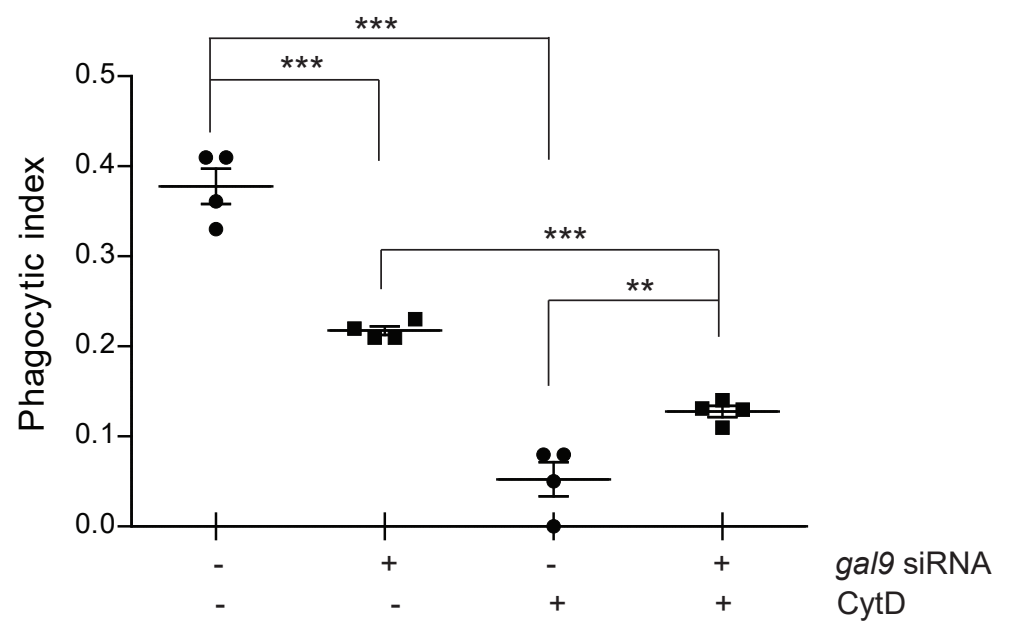




\section{Supplemental figure legends}

Figure S1. gal9 and gal3 siRNA do not cause non-specific effects, Related to Figure 1. A and B moDCs were transfected with gal9 siRNA and/or gal3 siRNA or a non-targeting siRNA (NT). Total (A) or surface bound (B) Galectin-9 and Galectin-3 knockdown were confirmed by flow cytometry $48 \mathrm{~h}$ after transfection. NT siRNA (grey area), gal9 siRNA or gal3 siRNA transfected moDCs (red area), gal9 and gal3 siRNA transfected moDCs (blue area). Black dotted line represents isotype control. Numbers in inset indicate geometrical Mean fluorescence intensity (gMFI). C. moDCs were transfected as above and surface levels of Galectin-9 and Galectin-3 assessed by flow cytometry. Grey area represent levels of Galectin-9 and Galectin-3 in NT siRNA transfected cells and black dotted line=isotype control. Numbers in inset indicate gMFI. In left panel: orange area shows levels of Galectin-9 in gal3 siRNA transfected cells. Red area depicts Galectin-3 levels in gal9 siRNA transfected cells. In right panel: organge area represents Galectin-3 levels in gal9 siRNA transfected cells and red area shows Galectin9 levels in ga/3 siRNA transfected cells.

Figure S2. Galectin-9 is depleted in dendritic cells upon gal9 siRNA transfection and lactose treatment, Related to Figure 2. A moDCs were treated with $35 \mathrm{mM}$ lactose for $48 \mathrm{~h}$ and removal of extracellular Galectin-9 expression was confirmed by flow cytometry. Black population = untreated cells; purple population = lactose treated cells; black dotted line population $=$ isotype control. Numbers in inset indicate gMFI. Panels depicts representative results for one donor. B. moDCs were transfected with gal9 siRNA or a NT siRNA. Galectin-9 knockdown was confirmed by flow cytometry 48 hours after transfection. NT (grey area) or gal9 siRNA-transfected moDCs (red area). Black dotted line represents isotype control values. Numbers in inset indicate gMFI. C. Total lysates from NT and gal9 siRNA transfected cells were subjected to Western Blot and Galectin-9 expression was analysed. Tubulin was used as loading control. Band intensities were quantified using ImageJ and normalised for tubulin. D. NT or gal9 siRNA-transfected cells were challenged with zymosan for $60 \mathrm{~min}$. After this time, cells were fixed, stained and binding index calculated for each frame analysed. Data represents mean average binding index \pm SEM of three independent donors. Twenty frames were analysed for each donor and transfection. E. Representative images from NT or gal9 siRNA-transfected moDCs 60 min after being challenged with zymosan. Scale bar: $25 \mu \mathrm{m}$.

Figure S3. Galectin-9 knockdown does not affect cell surface or intracellular DC-SIGN levels, Related to Figure 2. moDCs were transfected with either NT or gal9 siRNA and the cell surface levels of Galectin-9 and DC-SIGN analysed $24 \mathrm{~h}$ (A and B), 48 (C and D) and $72 \mathrm{~h}$ (E and F) after transfection by flow cytometry. $\mathbf{G}$ and $\mathbf{H}$. Intracellular levels of Galectin-9 $(\mathbf{G})$ and DC-SIGN (H) were analysed $48 \mathrm{~h}$ after transfection with either NT or gal9 siRNA by flow cytometry. Each symbol represents one independent donor and lines connect paired NT and gal9 siRNA-transfected moDCs. Data represents mean average expression levels \pm SEM. For statistical analysis, paired students $t$-test was conducted between NT and gal9 siRNA-transfected cells. n.s. $p>0.05,{ }^{* *} p<0.005,{ }^{* * *} p<0.001$. 
Figure S4. DC-SIGN is essential for particle uptake in DCs, Related to Figure 2. A and B moDCs were transfected with gal9 or a NT siRNA. Forty-eight hours later cells were incubated with AZN-D1 or isotype control (mlgG1) for $10 \mathrm{~min}$ prior to being challenged with zymosan for $60 \mathrm{~min}$. Cells were then fixed, stained and the phagocytic index calculated. Graph and panels show representative results for one donor out of three independent experiments. Scale bar: $25 \mu \mathrm{m}$. C Quantification and statistical analysis of experiments shown in (A). Data represents mean average phagocytic index \pm SEM of three independent donors. Results show the mean value \pm SEM of three independent donors. Unpaired students t-test was conducted between NT and gal9 siRNA-transfected cells. n.s $p>0.05,{ }^{*} p<0.05$, ${ }^{* *}$ $p<0.005,{ }^{* * *} p<0.001$.

Figure S5. Decreasing extracellular galectins by lactose does not alter the phagocytic ability of dendritic cells, Related to Figure 4. A. moDCs were treated with $35 \mathrm{mM}$ lactose for $48 \mathrm{~h}$ and removal of extracellular Galectin-9 and Galectin-3 expression was confirmed by flow cytometry. Blue population = untreated cells; magenta population = lactose treated cells; black population = isotype control. Numbers in inset indicate gMFI. Panels depict representative results for one experiment out of three independent experiments. B. Control or lactose-treated cells were challenged with zymosan alone or in combination with $35 \mathrm{mM}$ lactose for $60 \mathrm{~min}$. Cells were then fixed, stained and the phagocytic index calculated. Graph shows representative results for one donor. Each dot represents phagocytic index obtained for each microscopical field, each of which contained 10-20 cells. C. Graph shows the mean value \pm SEM for three independent donors. Unpaired students t-test was conducted between untreated control and lactose-treated cells. n.s $p>0.05$.

Figure S6. Treatment with cytochalasin D does not affect cell viability, Related to Figure 5. A and B. NT or gal9 siRNA-transfected moDCs were pre-treated with $1.25 \mu \mathrm{g} / \mathrm{ml} \mathrm{cytD}$ for 5 (A) or $10 \mathrm{~min}$ (B) prior to being challenged with zymosan for $30 \mathrm{~min}$. Cells were then fixed, stained and the phagocytic index calculated. Forty frames were analysed for each condition and donor. Data represents mean phagocytic index \pm SEM for one representative donor out of two independent experiments. C. moDCs transfected as per (A) were treated with $5 \mu \mathrm{g} / \mathrm{ml}$ cytochalasin $D($ cytD) for $10 \mathrm{~min}$. After this time cells were subjected to propidium iodide (PI) and Annexin V-FITC double staining for flow cytometry and percentage of apoptotic and necrotic cells calculated. One representative donor out-of-three independent experiments is shown. D. moDCs were transfected as in (A) and pre-treated with $2.5 \mu \mathrm{g} / \mathrm{ml}$ cytD for $10 \mathrm{~min}$ prior to being challenged with zymosan for $60 \mathrm{~min}$. Cells were fixed, stained and the phagocytic index calculated. Twenty frames were analysed for each condition and donor. Data represents mean average phagocytic index \pm SEM for one representative donor out-of-four independent experiments. 


\section{$\underline{\text { Transparent Methods }}$}

\section{Generation of monocyte-derived dendritic cells}

Dendritic cells were derived from peripheral blood monocytes isolated from a buffy coat (Sanquin, Nijmegen, The Netherlands) (de Vries et al., 2002). Monocytes isolated from healthy blood donors (informed consent obtained) were cultured for up to five days in RPMI 1640 medium (Life Technologies, Bleiswijk, Netherlands) containing $10 \%$ foetal bovine serum (FBS, Greiner Bio-one, Alphen aan den Rijn, Netherlands), $1 \mathrm{mM}$ ultra-glutamine (BioWhittaker), antibiotics (100 U/ml penicillin, $100 \mu \mathrm{g} / \mathrm{ml}$ streptomycin and $0.25 \mu \mathrm{g} / \mathrm{ml}$ amphotericin B, Life Technologies), IL-4 (500 U/ml) and GMCSF $(800 \mathrm{U} / \mathrm{ml})$ in a humidified, $5 \% \mathrm{CO}_{2}$. On day 3 , moDCs were supplemented with new IL-4 (300 $\mathrm{U} / \mathrm{ml})$ and $\mathrm{GM}-\mathrm{CSF}(450 \mathrm{U} / \mathrm{ml})$.

\section{Generation of bone marrow-derived dendritic cells}

Galectin-9-deficient mice were kindly provided by GalPharma (Takamatsu, Japan) and were described elsewhere (Seki et al., 2008). To generate bone marrow-derived DCs (BMDCs), bone marrow cells from mouse femurs were cultured in RPMI 1640 medium supplemented with 10 \% FCS, $1 \mathrm{mM}$ ultra-glutamine, antibiotics, and B-mercaptoethanol in the presence of $20 \mathrm{ng} / \mathrm{ml}$ GM-CSF (PeproTech) for 8 days to generate GM-CSF BMDCs.

\section{Infection model and cytokine measurements}

Wild-type C57BL/6J (Charles River) and galectin-9 null mice were maintained under specific pathogen-free conditions at the Central Animal Laboratory (Nijmegen, the Netherlands). Drinking water and food were provided ad libitum. The experiments were performed according to guidelines for animal care of the Nijmegen Animal Experiments Committee and in accordance with the ethical standards described in the declaration of Helsinki. Endotoxin-free Candida albicans was prepared as described previously (van Spriel et al., 1999). Yeast cells were heat-inactivated by incubating them at $65^{\circ} \mathrm{C}$ for 90 minutes. Animals were injected with $12 \times 10^{6}$ heat-inactivated Candida albicans in a volume of $200 \mu \mathrm{l}$ PBS intravenously and $3 \times 10^{6}$ in $50 \mu$ PBS subcutaneously. Three hours after injection, spleen and popliteal lymph nodes were isolated and meshed to obtain single cell suspension. Spleen and lymph node cells were meshed through a $100 \mu \mathrm{m}$ cell strainer by using a syringe plunger. Cell suspension was spun at $400 \mathrm{xg}$ for $5 \mathrm{~min}$ and resuspended in $3 \mathrm{ml}$ of $1 \mathrm{x}$ ammonium chloride solution for the lysis of erythrocytes. After $3 \mathrm{~min}$ of incubation at room temperature cells were washed with $20 \mathrm{ml}$ of PBS 2 times. To analyse cytokine secretion, $380 \times 10^{3} \mathrm{lymph}$ node cells or $1 \times 10^{6}$ spleen cells were seeded into 96 -well plates for $24 \mathrm{~h}$ after which supernatants were collected and stored at $-20^{\circ} \mathrm{C}$. Spleen samples were re-challenged with $1 \times 10^{6} \mathrm{C}$. albicans prior to being seeded for $24 \mathrm{~h}$ and supernatants collected. The levels of IL-12 and TNFa in the supernatants of spleen and lymph node homogenates were determined using a commercial ELISA kits (ThermoFisher Scientific). Standard curves were run at the same time and were used to calculate the concentration of cytokines in the samples.

\section{Antibodies and reagents}

The following primary antibodies were used for Western Blotting: rabbit anti-DC-SIGN (H200, Santa Cruz, Heidelberg, Germany) at 1:2000 (v/v), goat anti-Galectin-9 (AF2045, R\&D systems, Minneapolis, Minnesota) at 1:1000 (v/v) and rat anti-tubulin (Novus Biological, Abingdon, United Kingdom) at 1:2000 (v/v). The following secondary antibodies were used: donkey anti-rabbit IRDye 680 
926-32223, Li-Cor, Lincoln, Nebraska), donkey anti-goat IRDye 680 (920-32224, Li-Cor), goat anti-rat IRDye 680 (A21096, Invitrogen, Landsmeer, Netherlands). All secondary antibodies were used at $1: 5000(\mathrm{v} / \mathrm{v})$.

The following antibodies were used for fluorescence microscopy: mouse IgG2B anti-human DCSIGN at $2 \mu \mathrm{g} / \mathrm{ml}$ (DCN46, BD Biosciences, Breda, Netherlands), mouse IgG1 anti-human AZN-D1 at 2 $\mu \mathrm{g} / \mathrm{ml}$ (Geijtenbeek et al., 2000), goat anti-human Galectin-9 at $20 \mu \mathrm{g} / \mathrm{ml}$ (AF23045, R\&D systems); mouse monoclonal Rac1 (240106; Cell Biolabs) at 1:100, TfR (sc-65877, Santa Cruz) at 1:200, antiFITC Alexa fluor 647 (Jackson ImmunoResearch, Huissen, Netherlands; 200-602-037) at 1:200. The following secondary antibodies were used: donkey anti-mouse IgG Alexa 647 (A31571), goat antimouse IgG1 Alexa 488 (A21121), donkey-anti goat IgG Alexa 488 or 647 (A11055 and A21447), rabbit anti-mouse IgG Alexa 488 (A21204) and goat anti-mouse IgG2B Alexa 647 (A21242). All secondary antibodies were purchased from Life Technologies and used at 1:400 dilution (v/v). For F-actin staining Alexa fluor-647 phalloidin (A22287, Thermofisher) or Alexa fluor-568 phalloidin (A12380, Thermofisher) were used at 1:100 dilution (v/v). To inhibit specific cytoskeleton components cytochalasin $D$ was used (C8273, Sigma-Aldrich, Zwijndrecht, Netherlands) at a final concentration of 1.25 or $2.5 \mu \mathrm{g} / \mathrm{ml}$.

\section{Small interfering RNA knockdown}

On day 3 of DC differentiation, cells were harvested and subjected to electroporation. For Galectin-9 and Galectin-3 silencing, three custom stealth small interfering RNA (siRNA) were used. For Galectin-9 LGALS9HSS142807, LGALS9HSS142808 and LGALS9HSS142809 were used and for Galectin-3 LGALS3HSS180668, LGALS3HSS180670, LGALS3HSS180669 (Invitrogen). Equal amounts of the siRNA ON-TARGETplus non-targeting (NT) siRNA\#1 (Thermo Scientific) were used as control. Cells were washed twice in PBS and once in OptiMEM without phenol red (Invitrogen). For silencing each Galectin, a total of $15 \mu \mathrm{g}$ siRNA ( $5 \mu \mathrm{g}$ from each siRNA) was transferred to a 4-mm

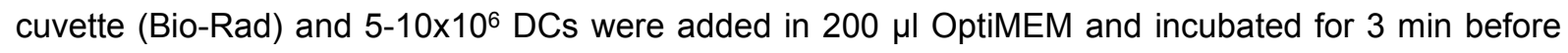
being pulsed with an exponential decay pulse at $300 \mathrm{~V}, 150 \mathrm{mF}$, in a Genepulser Xcell (Bio-Rad, Veenendaal, Netherlands), as previously described (Schuurhuis et al., 2009). Immediately after electroporation, cells were transferred to preheated $\left(37^{\circ} \mathrm{C}\right)$ phenol red-free RPMI 1640 culture medium supplemented with $1 \%$ ultraglutamine, $10 \%$ (v/v) FCS, IL-4 (300 U/ml), and GM-CSF (450 U/ml) and seeded at a final density of $5 \times 10^{5}$ cells $/ \mathrm{ml}$.

\section{Co-Immunoprecipitation and Western Blotting}

Endogenous DC-SIGN was immunoprecipitated from lysates of moDCs (day 6) untreated or treated with $35 \mathrm{mM}$ lactose for $48 \mathrm{~h}$. Cells $\left(10 \times 10^{6}\right)$ were detached using cold PBS, collected and lysed in $1 \mathrm{ml}$ lysis buffer containing $150 \mathrm{mM} \mathrm{NaCl}, 10 \mathrm{mM}$ Tris-HCl (pH 7.5), $2 \mathrm{mM} \mathrm{MgCl}, 1$ \% Brij97, $2 \mathrm{mM}$ $\mathrm{CaCl}_{2}, 5 \mathrm{mM} \mathrm{NaF}, 1 \mathrm{mM} \mathrm{NaVO}_{4}$ and $1 \mathrm{mM} \mathrm{PMSF}$ for $30 \mathrm{~min}$ on ice. Cell lysates were pre-cleared with $3 \% \mathrm{BSA}$ and isotype control-coated Dynabeads (Invitrogen). Lysates were then incubated with $2 \mu \mathrm{g}$ of anti-DC-SIGN (H200, SantaCruz) or isotype control under rotation. After incubating for $1 \mathrm{~h}$ at $4{ }^{\circ} \mathrm{C}$, dynabeads were added and samples were further incubated for $1.5 \mathrm{~h}$. Afterwards, beads were washed five times in washing buffer ( $150 \mathrm{mM} \mathrm{NaCl}, 10 \mathrm{mM}$ Tris- $\mathrm{HCl}(\mathrm{pH} 7.5), 2 \mathrm{mM} \mathrm{MgCl}_{2}, 0.1 \% \mathrm{Brij}$, $2 \mathrm{mM}$ $\mathrm{CaCl}_{2}, 5 \mathrm{mM} \mathrm{NaF}, 1 \mathrm{mM} \mathrm{NaVO}$ and $1 \mathrm{mM} \mathrm{PMSF}$ ) and bound proteins eluted in SDS sample buffer (62.5 mM Tris pH 6.8, 2 \% SDS, 10 \% glycerol). For immunoprecipitations performed on lactose-treated 
cells, $35 \mathrm{mM}$ lactose was added to the lysis and wash buffer. Proteins were separated by PAGE and blotted onto PVDF membranes. Membranes were blocked in TBS containing $3 \%$ BSA and $1 \%$ skim milk powder at room temperature for $1 \mathrm{~h}$ prior to be stained with specific antibodies against DC-SIGN and Galectin-9. Antibody signals were detected with HRP coupled secondary antibodies and developed using Odyssey CLx (Li-Cor) following manufacturer's instructions. Images were retrieved using the Image Studio Lite 5.0 software.

\section{Uptake assay and immunofluorescence}

$2 \times 10^{5}$ moDCs transfected with either non-targeting (NT) or gal9 siRNA were seeded in phenol red free RPMI containing $10 \%$ FBS, 1 mM ultra-glutamine, antibiotics, IL-4 (500 U/ml) and GM-CSF $(800 \mathrm{U} / \mathrm{ml})$ in a humidified, $5 \% \mathrm{CO}$-containing atmosphere for 48 hours. After this time, cells were washed with serum free RPMI and challenged with $1 \times 10^{6}$ zymosan-FITC (ThermoFisher scientific) for 15,30 or $60 \mathrm{~min}$, after which moDCs were washed extensively with PBA and fixed with $4 \%$ paraformaldehyde (PFA). When appropriate, cells were incubated with $20 \mu \mathrm{g} / \mathrm{ml}$ of anti-DC-SIGN (AZND1) or isotype control for $10 \mathrm{~min}$ prior to the addition of the zymosan-FITC particles. For experiments performed using cytoskeleton-blocking agents, cells were incubated with either 1.25 or $2.5 \mu \mathrm{g} / \mathrm{ml}$ of cytochalasin $\mathrm{D}$ for $10 \mathrm{~min}$ prior to the addition of zymosan-FITC particles. For lactose blocking experiments, moDCs were treated with growth medium containing $35 \mathrm{mM}$ of lactose for $48 \mathrm{~h}$. After this time, cells were detached and challenged in suspension with zymosan_FITC particles for 45 min prior to being seeded on Poly-L-Lyisine-coated coverslips. Cells were left to attach to the coverslip for further $15 \mathrm{~min}$ in the presence of zymosan prior to being fixed with $4 \%$ PFA and stained as above.

For immunofluorescence staining, samples were incubated without permeabilisation with an anti-FITC AF647 antibody (200-602-037, Jackson) at 1:200 (v/v) for $30 \mathrm{~min}$ at room temperature followed by DAPI staining (Sigma-Aldrich) at 1:3000 (v/v) for $10 \mathrm{~min}$ and at room temperature. Cells were then washed twice with PBS, one time with milliQ $\mathrm{H}_{2} \mathrm{O}$, embedded onto glass slides using Mowiol (Calbiochem) and stored at $-20^{\circ} \mathrm{C}$ until imaging. Samples were imaged with a Leica DMI6000 epifluorescence microscope fitted with a 63x 1.4 NA oil immersion objective, a metal halide EL6000 lamp for excitation, a DFC365FX CCD camera and GFP and DsRed filter sets (all from Leica, Wetzlar, Germany). Focus was kept stable with the adaptive focus control from Leica. Images were analysed with ImageJ software. Twenty to thirty frames were analysed for each condition and the phagocytic index ((total number of particles -total number of membrane-bound particles)/number of cells) and the binding index (number or bound particles/number of cells) calculated for each frame.

\section{Flow cytometry}

Single cell suspensions were stained with specific antibodies or isotype control as negative control for $30 \mathrm{~min}$ at $4{ }^{\circ} \mathrm{C}$. The following antibodies were used: mouse-anti DC-SIGN (clone AZN-D1, (Geijtenbeek et al., 2000)) at $5 \mu \mathrm{g} / \mathrm{ml}$; goat anti-Galectin-9 (AF2045, R\&D systems) at $20 \mu \mathrm{g} / \mathrm{ml}$. Before staining, moDCs and U-937 cells were incubated with $2 \%$ human serum for $10 \mathrm{~min}$ on ice to block nonspecific interaction of the antibodies with FcRs. All secondary antibodies were conjugated to Alexa Fluor 488 or Alexa Fluor 647 dyes (Invitrogen) and used at dilutions 1:400 (v/v). All antibody incubations were performed in PBA containing $2 \%$ human serum. Unless otherwise stated, all flow cytometry stainings were performed against membrane-bound DC-SIGN and Galectin-9. For intracellular DC-SIGN and 
Galectin-9 stainings cells were fixed in $4 \%$ PFA (w/v) for $10 \mathrm{~min}$, permeabilised by incubation for 15 min with PBA containing $0.1 \%$ saponin (PBA-S) prior to being stained as before. For actin staining cells were fixed in $4 \%$ PFA (w/v) for $10 \mathrm{~min}$, permeabilised by incubation for $15 \mathrm{~min}$ with PBA containing 0.1 $\%$ saponin (PBA-S) and F-actin subsequently labelled with Alexa Fluor 647-labelled phalloidin in PBA$S$ for $20 \mathrm{~min}$ at room temperature. Cells were analysed with a FACSCalibur instrument (BD Biosciences) and results analysed using FlowJo version X software (Tree Star, Ashland, Oregon).

\section{Confocal microscopy}

gal9 or non-targeting siRNA -transfected moDCs were collected at day 5 and blocked with PBA $+1 \%$ human serum prior to being incubated with primary antibody for $30 \mathrm{~min}$ on ice. Cells were then washed and incubated for further 30 min with the corresponding secondary antibody followed by a 60 min incubation at $12^{\circ} \mathrm{C}$. Cells were then washed extensively, fixed in $2 \%$ PFA and allowed to attach on poly-L-lysine-coated $12 \mathrm{~mm}$ glass coverslips (Electron Microscopy Sciences, Hatfield, Pennsylvania) for $30 \mathrm{~min}$ at room temperature. After, cells were again fixed with $2 \%$ PFA for $20 \mathrm{~min}$, washed with PBS and coverslips embedded in glass slides using Mowiol prior to be stored at $4{ }^{\circ} \mathrm{C}$ until imaging. For actin staining, cells were fixed with $4 \%$ PFA for 20 min at $4{ }^{\circ} \mathrm{C}$, washed twice and permeabilised by incubation with PBA containing $0.1 \%$ saponin (PBA-S). F-actin was subsequently labelled with Alexa Fluor 647labelled phalloidin in PBA-S for $30 \mathrm{~min}$ at room temperature. Confocal images were obtained in a sequential manner using a commercial Olympus FV1000 Confocal Laser Scanning Microscope with Argon (457, 488, $515 \mathrm{~nm}$ ), and 405, 559 and 635 diode excitation lasers and a 60x oil immersion objective (UPlanSApo 60×/1.35 Oil). Images were obtained using the FW10-ASW software (Olympus, Nijmegen, Netherlands) and processed with Fiji software.

\section{Ventral plasma membrane staining and super resolution imaging}

$5 \times 10^{5}$ moDCs were seeded onto $25 \mathrm{~mm}$ glass coverslips (Electron Microscopy Sciences, Hatfield, Pennsylvania) in phenol red free RPMI containing $10 \%$ FBS, 1 mM ultra-glutamine, IL-4 (500 $\mathrm{U} / \mathrm{ml}$ ) and GM-CSF (800 U/ml) in a humidified, $5 \%$ CO2-containing atmosphere for 48 hours. After this time, ventral plasma membranes were prepared by sonication using a Sartorius Labsonic $\mathrm{P}$ sonicator with cycle set at 1 and amplitude at $20 \%$ output. First, the sonicator tip was placed in a glass beaker containing $100 \mathrm{ml}$ prewarmed hypotonic PHEM buffer (6 mM PIPES, $5 \mathrm{mM} \mathrm{HEPES,} 0.4 \mathrm{mM} \mathrm{Mg}_{2} \mathrm{SO}_{4}, 2$ mM EGTA). Next, coverslips were held $1-2 \mathrm{~cm}$ below the sonicator tip at a 45 degrees angle in the hypotonic PHEM solution and cells were sonicated for approximately 1 second. Directly after sonication coverslips were transferred to a pre-warmed PBS solution containing $4 \%$ paraformaldehyde and 0.05 $\%$ glutaraldehyde and incubated for $30 \mathrm{~min}$ at room temperature. For Galectin-9 and actin staining, coverslips were subsequently incubated with anti-Galectin-9 antibody (AF23045, R\&D systems) for $2 \mathrm{~h}$ at room temperature, washed and incubated for $1 \mathrm{~h}$ with the secondary antibody donkey-anti-goat Alexa $568(\mathrm{~A} 11057)$ at 1:200 (v/v) and Alexa Fluor 488-labelled phalloidin at 1:100 (v/v) followed by DAPI staining (Sigma-Aldrich) at 1:3000 (v/v) for $10 \mathrm{~min}$ and at room temperature. Cells were then washed twice with PBS, one time with milliQ $\mathrm{H}_{2} \mathrm{O}$, embedded onto glass slides using Mowiol (Calbiochem) and stored at $4{ }^{\circ} \mathrm{C}$ until imaging. Confocal images were obtained in a sequential manner using a commercial Zeiss LSM880 confocal scanning microscope equipped with an Airyscan Unit, 405 and $561 \mathrm{~nm}$ diode lasers, argon $(458,488,514 \mathrm{~nm})$ lasers and a $633 \mathrm{~nm}$ laser and a 63× Plan Apochromat (1.4 NA) oil 
immersion objective. Images were obtained using the ZEN software (Zeiss Microscopy, Breda, Netherlands) and processed with the ZEN Airyscan processing toolbox and Fiji software.

\section{Atomic force microscopy}

$6 \times 10^{5}$ moDCs transfected with either Non-Targeting or gal9 siRNA were seeded in phenol-red free RPMI supplemented as before in a $40 \mathrm{~mm}$ glass bottom dish (GWST-5040, WillCo, Amsterdam, Netherlands) for 48 hours. After this time, mechanical probing of cells was performed with a Catalyst BioScope (Bruker, Kalkar, Germany) atomic force microscope coupled to a confocal microscope (TCS SP5II, Leica) using the "point and shoot" feature of the Nanoscope software (Bruker). Silicon nitride cantilevers with nominal spring constants of $0.06 \mathrm{~N} / \mathrm{m}$ (S-NL type $\mathrm{D}$, Bruker) were used without any tip modification. The system was calibrated first in air and then in cell-free medium at $37^{\circ} \mathrm{C}$ prior to each experiment by measuring the deflection sensitivity on a glass surface, which enabled determination of the cantilever spring constant using the thermal noise method (te Riet et al., 2011). Before the sample was placed, the xy movement of the sample stage was calibrated using the NanoScope software. An optical image of the cells was captured after the tip position was registered, which allowed for selection of the point (or region) of interest on the optical image. Two force - distance curves were sequentially acquired from each point selected on the membranes of stretched cells and three independent points were probed for each cell. The forward (approach) and reverse (retraction) velocities were kept constant at $1 \mu \mathrm{m} / \mathrm{s}$, ramping the cantilever by $4 \mu \mathrm{m}$ with a $3 \mathrm{nN}$ threshold in a closed $\mathrm{z}$ loop. After baseline correction, approach curves were analysed for determination of Young's modulus of elasticity using Sneddon's conical indenter model (Sneddon, 1965) for which Poisson's ratio was set as 0.5 (Lin et al., 2007) and the half angle of the indenter as $18^{\circ}$. Contact point-independent linearised Sneddon equation was used for fitting the approach curves (van Helvert and Friedl, 2016). The region on the approach curve through which the model was fit was determined via setting the lower and upper boundaries that corresponded to approximately $10 \%$ and $70 \%$ of the difference between the maximum and minimum forces exerted, respectively. Two curves per point and 2-3 points per cell were averaged to obtain Young's modulus of elasticity per cell. Approximately 10 to 30 cells were analysed for each condition and experiment.

\section{Rac1-GTPase activation assay}

To assess GTP-bound Rac1 levels, colorimetric G-LISA activity assay kit (BK128-S, Cytoskeleton, Denver, Colorado) was used according to manufacturer's instructions. Day 5 moDCs were stimulated with zymosan particles (Z4250, Sigma-Aldrich) for 5, 15 or 30 min prior to being lysed in icecold lysis buffer, snap-frozen in liquid nitrogen and stored at $-80{ }^{\circ} \mathrm{C}$. Protein concentrations were determined using the micro BCA protein assay kit (23235, ThermoFisher scientific) and $50 \mu \mathrm{g}$ of total protein were subsequently used for the G-LISA assay. Rac1-GTP levels were determined using the Rac1-GTP binding 96-well plates. Absorption of the wells at $490 \mathrm{~nm}$ was determined with an iMark microplate reader (BioRad).

\section{Statistical analysis}

All data was processed using Excel 2013 (Microsoft) and GraphPad Prism 5 software. All Image processing was performed on ImageJ software and statistical analysis was done using Prism5. The 
specific statistical test used is described for each figure in the figure legend. $p$ values $<0.05$ were considered statistically significant.

\section{Supplemental References}

DE VRIES, I. J., EGGERT, A. A., SCHARENBORG, N. M., VISSERS, J. L., LESTERHUIS, W. J., BOERMAN, O. C., PUNT, C. J., ADEMA, G. J. \& FIGDOR, C. G. 2002. Phenotypical and functional characterization of clinical grade dendritic cells. J Immunother, 25, 429-38.

GEIJTENBEEK, T. B., TORENSMA, R., VAN VLIET, S. J., VAN DUIJNHOVEN, G. C., ADEMA, G. J., VAN KOOYK, Y. \& FIGDOR, C. G. 2000. Identification of DC-SIGN, a novel dendritic cellspecific ICAM-3 receptor that supports primary immune responses. Cell, 100, 575-85.

LIN, D. C., DIMITRIADIS, E. K. \& HORKAY, F. 2007. Robust strategies for automated AFM force curve analysis-II: adhesion-influenced indentation of soft, elastic materials. J Biomech Eng, 129, 90412.

SCHUURHUIS, D. H., VERDIJK, P., SCHREIBELT, G., AARNTZEN, E. H., SCHARENBORG, N., DE BOER, A., VAN DE RAKT, M. W., KERKHOFF, M., GERRITSEN, M. J., EIJCKELER, F., BONENKAMP, J. J., BLOKX, W., VAN KRIEKEN, J. H., BOERMAN, O. C., OYEN, W. J., PUNT, C. J., FIGDOR, C. G., ADEMA, G. J. \& DE VRIES, I. J. 2009. In situ expression of tumor antigens by messenger RNA-electroporated dendritic cells in lymph nodes of melanoma patients. Cancer Res, 69, 2927-34.

SEKI, M., OOMIZU, S., SAKATA, K. M., SAKATA, A., ARIKAWA, T., WATANABE, K., ITO, K., TAKESHITA, K., NIKI, T., SAITA, N., NISHI, N., YAMAUCHI, A., KATOH, S., MATSUKAWA, A., KUCHROO, V. \& HIRASHIMA, M. 2008. Galectin-9 suppresses the generation of Th17, promotes the induction of regulatory $\mathrm{T}$ cells, and regulates experimental autoimmune arthritis. Clin Immunol, 127, 78-88.

SNEDDON, I. N. 1965. The relation between load and penetration in the axisymetric boussinesq problem for a punch of arbitrary profile. International Journal of Engineering Science, 3, 10.

TE RIET, J., KATAN, A. J., RANKL, C., STAHL, S. W., VAN BUUL, A. M., PHANG, I. Y., GOMEZCASADO, A., SCHON, P., GERRITSEN, J. W., CAMBI, A., ROWAN, A. E., VANCSO, G. J., JONKHEIJM, P., HUSKENS, J., OOSTERKAMP, T. H., GAUB, H., HINTERDORFER, P., FIGDOR, C. G. \& SPELLER, S. 2011. Interlaboratory round robin on cantilever calibration for AFM force spectroscopy. Ultramicroscopy, 111, 1659-69.

VAN HELVERT, S. \& FRIEDL, P. 2016. Strain Stiffening of Fibrillar Collagen during Individual and Collective Cell Migration Identified by AFM Nanoindentation. ACS Appl Mater Interfaces, 8, 21946-55.

VAN SPRIEL, A. B., VAN DEN HERIK-OUDIJK, I. E., VAN SORGE, N. M., VILE, H. A., VAN STRIJP, J. A. \& VAN DE WINKEL, J. G. 1999. Effective phagocytosis and killing of Candida albicans via targeting FcgammaRI (CD64) or FcalphaRI (CD89) on neutrophils. J Infect Dis, 179, 661-9. 